\title{
EFEITOS DA SELEÇÃO PARA PESO PÓS-DESMAME SOBRE CARACTERÍSTICAS DE CARCAÇA, RENDIMENTO DE CORTES E COMPOSIÇÃO CORPORAL DE BOVINOS NELORE E CARACU, SOB ALIMENTAÇÃO RESTRITA E
}

Ad Libitum

SARAH FIGUEIREDO MARTINS BONILHA

Dissertação apresentada à Escola Superior de Agricultura "Luiz de Queiroz", Universidade de São Paulo, para obtenção do título de Mestre em Agronomia, Área de Concentração: Ciência Animal e Pastagens.

P I R A C I C A B A

Estado de São Paulo - Brasil

Junho - 2003 


\title{
EFEITOS DA SELEÇÃO PARA PESO PÓS-DESMAME SOBRE CARACTERÍSTICAS DE CARCAÇA, RENDIMENTO DE CORTES E COMPOSIÇÃO CORPORAL DE BOVINOS NELORE E CARACU, SOB ALIMENTAÇÃO RESTRITA E
} Ad Libitum

\section{SARAH FIGUEIREDO MARTINS BONILHA}

Engenheiro Agrônomo

\author{
Orientador: Prof. Dr. IRINEU UMBERTO PACKER
}

Dissertação apresentada à Escola Superior de Agricultura "Luiz de Queiroz", Universidade de São Paulo, para obtenção do título de Mestre em Agronomia, Área de Concentração: Ciência Animal e Pastagens.

P I R A C I C A B A

Estado de São Paulo - Brasil

Junho - 2003 


\section{Dados I nternacionais de Catalogação na Publicação (CIP)}

DI VSÃO DE BI BU OTECAE DOCUMENTAÇÃO - ESALQ/ USP

\section{Bonilha, Sarah Figueiredo Martins}

Efeitos da seleção para peso pós-desmame sobre características de carcaça, ren-dimento de cortes e composição corporal de bovinos Nelore e Caracu, sob alimen- tação restrita eAd Libitum/ Sarah Figueiredo Martins Bonilha. - -

Piracicaba, 2003.

$55 \mathrm{p}$. 2003.

Dissertação (mestrado) - - Escola Superior de Agricultura Luiz de Queiroz, Bibliografia.

1. Bovinos 2. Carcaça 3. Carne bovina- Qualidade 4. Composição corporal 5. Melr ramento genético animal I. Título

CDD 636.2082 


\section{DEDICO}

Aos meus pais Luiz e Maria Alice,

pelos exemplos de trabalho e força de vontade,

e pelas muitas palavras de estímulo.

\section{OFEREÇO}

Aos meus irmãos Gabriel, Eduardo e Rodolfo,

pelo carinho e incentivo durante a edição deste

trabalho e a concretização deste título. 


\section{AGRADECIMENTOS}

À Deus, pela minha vida, por tanto amparo e proteção em todos os momentos.

Ao grande mestre e orientador, Dr. Irineu Umberto Packer, Professor Titular do Departamento de Zootecnia da Escola Superior de Agricultura "Luiz de Queiroz", Universidade de São Paulo, pela orientação, confiança, oportunidade de trabalho e amizade.

Aos pesquisadores do Instituto de Zootecnia, Dr. Alexander George Razook, Dr. Guilherme Fernando Alleoni e Dr. Flávio Dutra Resende, pela atenção, amizade e grande ajuda na parte experimental e nas análises laboratoriais.

Aos funcionários do Instituto de Zootecnia, "Muzambinho", Dona Olinda, "Assobio", "Tonha", "Zezé”, Dona Floripes, Dona Antônia e Dona Luzia pela amizade, colaboração e auxílio durante as diversas fases do experimento.

Aos estagiários das mais diversas escolas e cursos que com pequenas ações contribuíram muito.

Às secretárias, Vera e Cláudia, e ao funcionário José Henrique, do Departamento de Zootecnia da ESALQ-USP, pela atenção dispensada.

Às bibliotecárias da ESALQ-USP, Eliana e Sílvia, pela revisão da dissertação. 
À professora Lídia, minha querida tia, pelo grande auxílio nas correções gramaticais.

Aos amigos Cláudia, Juliana, Aline, Itiberê, Cláudio, José Otávio, Flávio, Adriana, Juliano, Carlos Eduardo, Liliana, Liana, Andréa, Erica, "Batata", Rodrigo e "Biológico", do curso de pós-graduação em Ciência Animal e Pastagens da ESALQUSP, por todos os bons momentos juntos que fizeram os dias de trabalho tão especiais.

À Escola Superior de Agricultura "Luiz de Queiroz", Universidade de São Paulo (ESALQ-USP), ao Instituto de Zootecnia (IZ) e ao Frigorífico Minerva, pela confiança e apoio demonstrados neste trabalho.

Ao suporte financeiro concedido pela CAPES, para o aprimoramento de meus conhecimentos e obtenção do título de Mestre. 


\section{SUMÁRIO}

Página

LISTA DE TABELAS............................................................................... viii

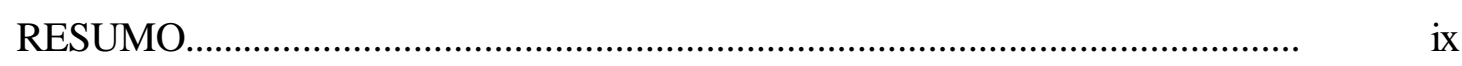

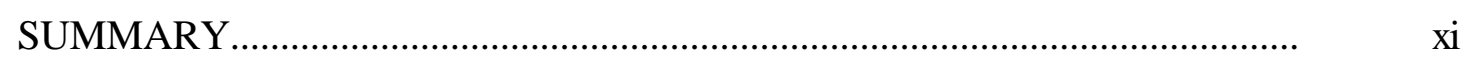

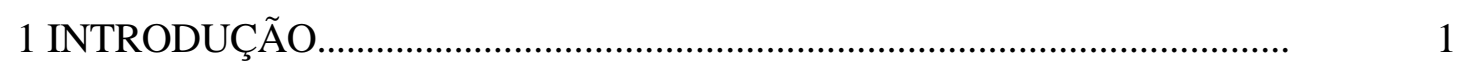

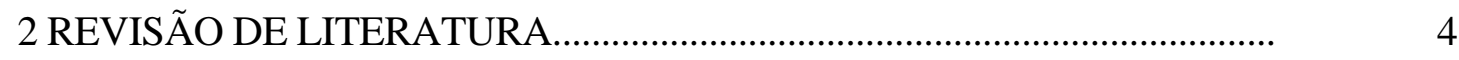

3 EFEITOS DA SELEÇÃO PARA PESO PÓS-DESMAME SOBRE CARACTERÍSTICAS DE CARCAÇA E DE QUALIDADE DE CARNE.......... 10

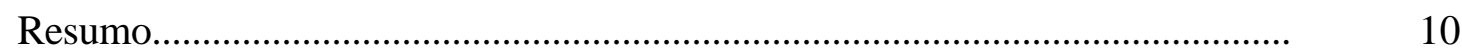

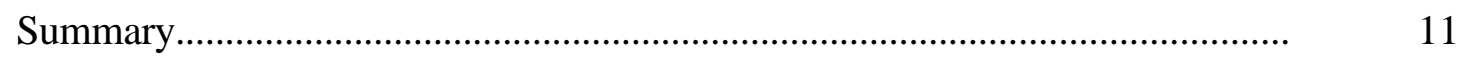

3.1 Introdução................................................................................................ 12

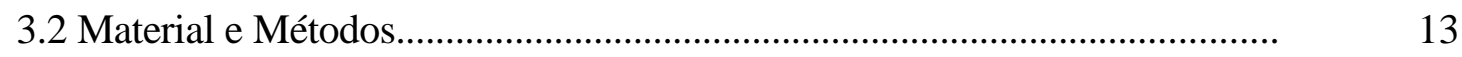

3.3 Resultados e Discussão............................................................................... 15

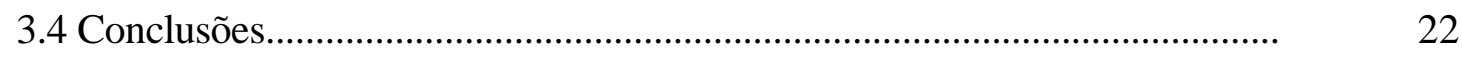

4 EFEITO DA SELEÇÃO PARA PESO PÓS-DESMAME SOBRE A COMPOSIÇÃO CORPORAL DE BOVINOS.................................................. 23

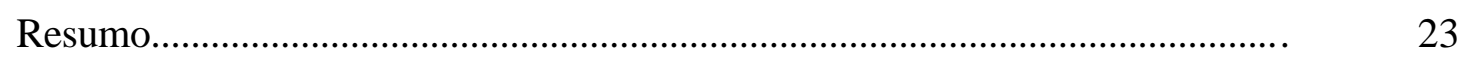

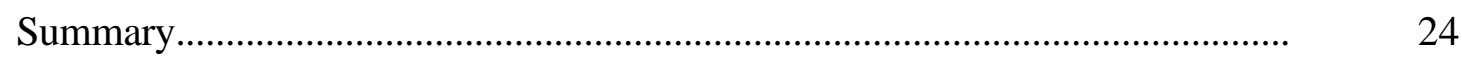

4.1 Introdução.......................................................................................

4.2 Material e Métodos................................................................................ 26

4.3 Resultados e Discussão............................................................................. 29

4.4 Conclusões.............................................................................................. 33

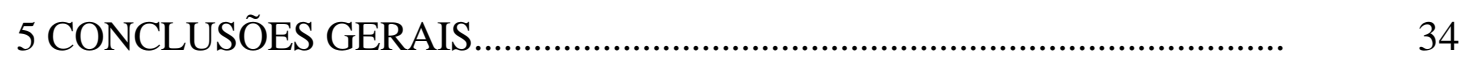


ANEXOS.

35

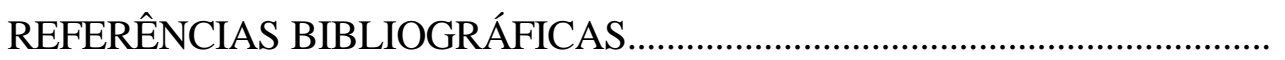




\section{LISTA DE TABELAS}

Página

1 Médias dos tempos de confinamento (dias), dos pesos vivos ao abate (kg),dos pesos das meias carcaças direitas resfriadas $(\mathrm{kg})$ e dos pesos $(\mathrm{kg})$ e rendimentos $(\%)$ dos cortes primários

2 Médias, em \%, da porção comestível, ossos e aparas, obtidos na meia carcaça direita dos bovinos, e em seus respectivos quartos

3 Pesos médios dos cortes aparados, em kg, retirados da meia carcaça direita dos bovinos

4 Força de cisalhamento $(\mathrm{kg})$, perdas no cozimento (\%), área de olho de lombo $1\left(\mathrm{~cm}^{2}\right)$, área de olho de lombo $2\left(\mathrm{~cm}^{2} / 100 \mathrm{~kg}\right.$ de carcaça) e espessura de gordura (mm), medidas no contra filé dos bovinos.

5 Tempos de confinamento (dias), pesos vazios inicial $(\mathrm{kg})$ e final $(\mathrm{kg})$ dos animais Caracu, Nelore Seleção e Nelore Controle

6 Taxas de ganho de peso vazio $(\mathrm{kg} / \mathrm{dia})$, dos constituintes químicos corporais (g/dia) e de energia (Mcal/dia) em animais Caracu, Nelore Seleção e Nelore Controle.

7 Composição do corpo vazio, em \%, dos animais Caracu, Nelore Seleção e Nelore Controle.

8 Composição do ganho do corpo vazio, em constituintes químicos (\%) e energia (Mcal/dia), de animais Caracu, Nelore Seleção e Nelore Controle........ 


\section{EFEITOS DA SELEÇÃO PARA PESO PÓS-DESMAMESOBRE \\ CARACTERÍSTICAS DE CARCAÇA, RENDIMENTO DE CORTES E \\ COMPOSIÇÃO CORPORAL DE BOVINOS NELORE E CARACU, SOB \\ ALIMENTAÇÃO RESTRITA E Ad Libitum.}

Autora: SARAH FIGUEIREDO MARTINS BONILHA

Orientador: Prof. Dr. IRINEU UMBERTO PACKER

\section{RESUMO}

Cinqüenta e seis machos inteiros provenientes dos rebanhos do projeto de melhoramento genético da Estação Experimental de Sertãozinho, selecionados ou não para peso aos 378 dias (P 378), nascidos em 1999, foram confinados na Estação Experimental de Colina. Utilizaram-se animais dos grupos genéticos Nelore Seleção $(\mathrm{NeS})$, Nelore Controle (NeC) e Caracu Seleção (Ca), os quais foram distribuídos, aleatoriamente, nas três categorias experimentais: grupo de abate inicial (AI), grupo de alimentação restrita (AR) e grupo de alimentação Ad Libitum (AL). Na categoria AI alocaram-se 4 animais por grupo genético e nas categorias AR e AL foram alocados 8 animais $\mathrm{Ca}$ e $\mathrm{NeS}$, e 6 animais $\mathrm{NeC}$. Determinou-se o período experimental pelo tempo de acabamento dos animais, ou seja, quando os garrotes atingiram, no mínimo, 4,0 mm de espessura de gordura subcutânea, avaliada por ultra-som, sobre o músculo Longissimus dorsi, na posição entre a $12^{\text {a }}$ e a $13^{\mathrm{a}}$ costelas. Ao término do período de adaptação, a categoria AI foi abatida e as outras duas (AR e AL) entraram no ensaio de 
alimentação. Repetiram-se as pesagens e medidas de ultra-som e escore corporal a cada 28 dias. Em cada grupo genético, à medida que o acabamento preconizado para cada animal da categoria AL foi atingido, o animal da categoria $\mathrm{AR}$ mais semelhante àquele quanto ao peso e condição corporal, no início do experimento, foi também abatido. Avaliaram-se em todos os animais características de carcaça, composição corporal e rendimento de cortes cárneos comerciais. Os dados foram analisados de acordo com esquema fatorial, utilizando dois tipos de alimentação e três grupos genéticos. Os animais $\mathrm{Ca}$ e $\mathrm{NeS}$ apresentaram maiores pesos de abate, requerendo mais tempo de confinamento para atingirem o ponto de acabamento preconizado. O maior peso de abate destes animais também influenciou outras características correlacionadas, como peso da carcaça, traseiro, dianteiro e ponta de agulha. Verificou-se que a seleção para peso pósdesmame aumentou o peso de abate, de carcaça e de seus cortes primários, porém os animais selecionados apresentaram carne menos macia, mas ainda dentro dos padrões de maciez considerados bons. Os valores médios para os componentes químicos do corpo vazio em porcentagem de água, gordura, proteína e cinzas foram: Ca $(60,4 ; 15,5 ; 19,7$; $4,4), \mathrm{NeS}(58,2 ; 19,4 ; 17,8 ; 4,6)$ e $\mathrm{NeC}(57,4 ; 20,2 ; 18,3 ; 4,1)$. As taxas médias de ganho de peso vazio ( $\mathrm{kg} / \mathrm{dia})$, água (g/dia), gordura (g/dia), proteína (g/dia), cinzas (g/dia) e energia (Mcal/dia) foram: Ca (1,01; 409; 382; 150; 70; 4,45), NeS $(1,00 ; 355 ; 482 ; 113$; $46 ; 5,19)$ e $\mathrm{NeC}(0,91 ; 301 ; 457 ; 103 ; 52 ; 4,91)$. A composição química média do ganho do corpo vazio, em porcentagem de água, gordura, proteína, cinzas e energia (Mcal/dia) foi: $\mathrm{Ca}(40,1 ; 36,8 ; 15,2 ; 8,0 ; 4,32), \mathrm{NeS}(35,8 ; 48,1 ; 11,3 ; 4,8 ; 5,19)$ e $\mathrm{NeC}(32,7 ; 49,5$; 12,0; 5,8; 5,36). A seleção para peso pós-desmame, visualizada na comparação entre os grupos Nelore, não promoveu alterações indiretas na composição corporal desses animais, porém aumentouthes o tamanho corporal, exigindo maior tempo de confinamento. Os animais $\mathrm{Ca}$, quando comparados aos Nelore apresentaram porcentagens menores de gordura e maiores de proteína no corpo vazio, fato que pode ser explicado pelo maior tamanho corporal desses animais. 


\title{
EFFECTS OF SELECTION FOR POST-WEANING WEIGHTS ON CARCASS \\ TRAITS, MEAT CUT YELDS AND BODY COMPOSITION OF NELLORE AND \\ CARACU BULLS, IN RESTRICT AND Ad Libitum FEEDING.
}

\author{
Author: SARAH FIGUEIREDO MARTINS BONILHA \\ Adviser: Prof. Dr. IRINEU UMBERTO PACKER
}

\section{SUMMARY}

Fifty six bulls, born in 1999, from Sertãozinho Experimental Station herds, selected or not for weight at 378 days of age (W 378), were feedlot at Colina Experimental Station. Animals of the genetic groups Nellore (NeS), Control Nellore $(\mathrm{NeC})$ and Caracu (Ca) were utilized. They were randomnly distributed in three experimental groups: initial slaughter group (AI), restricted feeding group (AR) and $\mathrm{A} d$ Libitum feeding group (AL). The AI class had 4 animals for each genetic group and AR and $\mathrm{AL}$ had $8 \mathrm{NeS}$ and $\mathrm{Ca}$, and 6 animals $\mathrm{NeC}$. Animals were slaughtered with $4.0 \mathrm{~mm}$ of fat thickness measured by ultrasound. After the adaptation period, the AI class was slaughtered and the other classes (AR and $\mathrm{AL}$ ) started the feedlot period. In each genetic group, when an animal of the AL class attained the desired ultrasonic fat thickness for slaughter, the animal of AR class with similar weight and body conditions score, at the experiment starting point, was also slaughtered. In all animals carcass traits, body composition and meat cuts income were evaluated. Data were analized according to factorial scheme including two type of diets and three genetic groups. The $\mathrm{Ca}$ and $\mathrm{NeS}$ 
bulls were heavier at slaughter requiring longer feeding period to attain the desired ultrasonic fat thickness. The heavier weights at slaughter of these animals also changed correlated traits as carcass, hindquater, forequarter and spare ribs weights. The selection for weight in the Nellore promoted higher slaughter, carcass and primary cuts weights, but selected animals had less tender meat, but inside good tender standards. Average values for chemical components of empty body weight, in percentages of water, fat, protein and ash were: $\mathrm{Ca}(60.4 ; 15.5 ; 19.7 ; 4.4), \mathrm{NeS}(58.2 ; 19.4 ; 17.8 ; 4.6)$ and $\mathrm{NeC}$ $(57.4 ; 20.2 ; 18.3 ; 4.1)$. The average rates of empty gain for body weight ( $\mathrm{kg} /$ day), water (g/day), fat (g/day), protein (g/day), ash (g/day) and energy (Mcal/day) were: Ca (1.01; $409 ; 382 ; 150 ; 70 ; 4,45)$, NeS $(1.00 ; 355 ; 482 ; 113 ; 46 ; 5,19)$ and $\mathrm{NeC}(0.91 ; 301 ; 457$; $103 ; 52 ; 4,91)$. The average rates of empty body gain chemical composition, in percentages of water, fat, protein, ash and energy (Mcal/day) were: $\mathrm{Ca}(40.1 ; 36.8 ; 15.2$; 8.0; 4.32), $\mathrm{NeS}(35.8 ; 48.1 ; 11.3 ; 4.8 ; 5.19)$ and $\mathrm{NeC}(32.7 ; 49.5 ; 12.0 ; 5.8 ; 5.36)$. The selection for post-weaning weights, observed by comparing the two Nellore groups, did not promote any change on body composition of these animals, but increased their body size, so they required longer feedlot period. The animals of genetic group $\mathrm{Ca}$, when compared with Nellore, had less fat and more protein, in percentages of empty body. It is due to their larger mature body size. 


\section{INTRODUÇÃO}

No moderno sistema produtivo de carne bovina, identifica-se a importância cada vez maior de produção eficiente, caracterizada pelo encurtamento do ciclo de produção e por produtos de melhor qualidade, obtidos pelo uso de animais geneticamente superiores, em condições ambientais adequadas.

A produtividade reside, basicamente, na qualidade do rebanho. Assim, procura-se selecionar aqueles animais com maior desempenho ponderal, precocidade sexual e alta eficiência reprodutiva, conversão eficiente dos alimentos em carne e de carcaça desejável. A precocidade de terminação expressa em dias para alcançar um grau de acabamento mínimo estipulado, juntamente com as características de desempenho, são importantes atributos econômicos a serem melhorados. A terminação deve ser representada por novilho que apresente, ao abate, carcaça com bom peso e dentro da especificação necessária para atender as exigências dos segmentos comercial e industrial.

Existem vários fatores, tais como raça, sexo e peso do animal, capazes de influenciar a tanto composição química, como as características de carcaça e rendimento de cortes cárneos dos bovinos. Inúmeras são as possibilidades de se trabalharem essas causas de variação, de forma a produzir as melhores combinações e, então, fazer delas o objetivo da pecuária de corte. Contudo, é importante que a seleção para composição desejável da carcaça esteja associada à eficiência produtiva e reprodutiva do gado de corte, para que os custos de produção da carne sejam minimizados. Daí, a necessidade de se definir as características desejáveis da carcaça bovina, para cada segmento de mercado, a partir dos recursos genéticos mais adaptados às condições tropicais brasileiras. 
No melhoramento dos bovinos, a avaliação genética permite identificar indivíduos superiores, que serão os pais da geração seguinte, ocasionando melhoria na qualidade do rebanho e aumentando a eficiência produtiva e econômica da pecuária de corte. Progressos notáveis têm sido verificados nos caracteres relacionados ao crescimento das raças zebuínas. Entretanto, o mesmo não pode ser dito a respeito do melhoramento genético das características de carcaça e qualidade da carne dos bovinos de corte. Este é um empreendimento bastante difícil e exige enfoques múltiplos no sentido de usar tanto as diferenças genéticas dentro da raça, como entre raças. As eventuais mudanças genéticas que podem estar ocorrendo na carcaça dos zebuínos são atribuídas a mudanças correlacionadas à seleção realizada para crescimento. Em algumas situações experimentais é possível avaliar a magnitude destas mudanças correlacionadas.

O projeto pioneiro de seleção nas raças zebuínas para crescimento pósdesmame, em andamento na Estação Experimental de Sertãozinho, do Instituto de Zootecnia, implementado a partir de 1976, tem como objetivo avaliar as respostas diretas à seleção fenotípica dentro de cada rebanho, e as respostas correlacionadas no crescimento, reprodução, eficiência alimentar e características de carcaça. As primeiras progênies deste projeto de pesquisa nasceram em 1981 e o mesmo continua, sem interrupção, até os dias atuais.

Vários trabalhos científicos, comparando o desempenho dos rebanhos selecionados e controle, publicados a partir de 1985, mostraram as mudanças diretas ocorridas no peso aos 378 dias e nas demais características de crescimento, como peso de abate, mudanças significativas na curva de crescimento, tamanho corporal e medidas de altura e comprimento do corpo (Packer et al., 1986; Razook et al., 1988 a, b; Razook et al., 1993; Razook et al.,1998; Cyrillo et al., 2000; Silva et al., 2000; Cyrillo et al., 2001; Mercadante et al., 2002 a, b; Razook et al., 2002; Mercadante et al., 2003).

Mais recentemente, trabalhos de pesquisa utilizando amostras de progênies do projeto, terminadas em confinamento, foram conduzidos com o objetivo de avaliar os efeitos da seleção sobre os caracteres de carcaça, rendimento de cortes e qualidade da carne (Alleoni et al., 1997b; Nardon et al., 1997; Nardon, 1998; Nardon et al., 1998; 
Razook et al., 2001a). Diferenças já podem ser observadas em alguns caracteres, porém estes trabalhos evidenciam a necessidade de estudos detalhados para monitorar as respostas correlacionadas na composição e qualidade da carne nos diferentes rebanhos, bem como a composição química e física da carcaça inteira de animais das linhas seleção e controle quando terminados em regimes diferentes de alimentação.

Tendo em vista estes antecedentes, este trabalho de pesquisa teve por objetivo específico avaliar os efeitos da seleção fenotípica para peso pós-desmame, dentro de rebanhos Nelore Seleção e Caracu, sobre as características de carcaça e rendimento de cortes cárneos comercias e sobre a composição química corporal de bovinos, em duas condições de regime alimentar. Para estes fins, esta dissertação é apresentada na forma de dois capítulos (Capítulos 3 e 4) referentes a artigos científicos distintos a serem publicados. 


\section{REVISÃO DE LITERATURA}

O projeto de melhoramento genético das raças zebuínas da Estação Experimental de Zootecnia de Sertãozinho, implementado a partir de 1976, tem por objetivo o aumento da taxa de crescimento dos animais, por meio da seleção para peso pós-desmame, em rebanhos das raças Nelore, Guzerá e Gir, além de estudar os efeitos desta seleção sobre eficiência alimentar, eficiência reprodutiva e características de carcaça. Além das raças zebuínas, também inclui um rebanho da raça Caracu, que é submetido aos mesmos critérios de seleção.

Nos rebanhos seleção, a cada ano são selecionados, com base no maior diferencial para peso padronizado aos 378 dias (no final da Prova de Ganho de Peso), três reprodutores e outros dois de reserva. No rebanho controle da raça Nelore, os reprodutores escolhidos possuem diferencial de seleção nulo ou próximo de zero. Além dos machos, são também selecionadas fêmeas para reposição de matrizes, com base no peso obtido a pasto aos 550 dias.

As mudanças genéticas, respostas diretas ou correlacionadas, nas características de crescimento, ocorridas nestes trabalhos têm sido amplamente divulgadas em diversas publicações (Packer et al., 1986; Razook et al., 1988 a, b; Razook et al., 1993; Razook et al.,1998, Silva et al., 2000). Mais recentemente, Cyrillo et al. (2000;2001) relataram tendências genéticas importantes no P378 de machos (2,7 a $3,08 \mathrm{~kg} / \mathrm{ano}$ ), bem como mudanças correlacionadas significativas na altura da garupa, comprimento do dorso, comprimento da garupa, distâncias entre ísquios e perímetro escrotal. Mercadante et al. (2003), utilizando a metodologia de modelo animal, demonstraram os resultados diretos e indiretos da seleção no tamanho adulto dos animais. 
Os avanços brasileiros, no melhoramento genético bovino, já apresentam resultados significativos na produção comercial, com melhoria evidente na fase de crescimento, e conseqüente redução na idade de abate e na taxa de desfrute dos animais, além das melhorias na conversão alimentar e nas características de carcaça.

Uma das grandes vantagens da seleção direta é melhorar o valor genético médio do rebanho. Espera-se que, em rebanhos submetidos à seleção, não só os reprodutores utilizados, como também os indivíduos acima da média no caráter selecionado, tenham valor genético diferenciado. Portanto, a utilização de touros de alto diferencial de seleção para peso promove desempenho superior em progênies produzidas em um rebanho distinto daquele em que foram selecionados, confirmando o valor da estimativa do mérito genético de tourinhos através de provas de ganho de peso (Razook et al., 1994).

Economicamente, a importância do peso à desmama está relacionada à idade do bezerro, pois quanto mais jovem ele for comercializado para recria e engorda, maior é a determinação do peso à desmama sobre o valor de comercialização. Razook et al. (1988 a,b) relataram resultados positivos de respostas direta e indireta, devidos à seleção para peso pós-desmame, dentro de rebanhos Nelore e Guzerá.

A taxa de crescimento, depois da taxa de reprodução, é o fator mais importante em uma exploração de bovinos de corte, e é avaliada, principalmente, por pesos a idades específicas ou idades a pesos específicos. Segundo Lanna (1997), o crescimento pode ser medido pelo aumento do peso vivo por unidade de tempo. Segundo Lanna \& Packer (1998), a pesquisa procura descrever a curva de crescimento pré e pós-natal e estudar os diferentes fatores que a influenciam. A maior parte das atividades desenvolvidas por produtores envolve a alteração nas curvas de crescimento. O objetivo é atingir pontos importantes desta curva, como maturidade sexual, peso e composição de carcaça, da forma mais rápida e econômica possível.

A curva de crescimento pode ser descrita por vários parâmetros, sendo dois deles os mais importantes. O primeiro deles relacionado ao peso adulto e o segundo, a taxa de maturidade, que é a velocidade com que o animal atinge o tamanho 
adulto. Estes dois parâmetros, quando analisados, permitem identificar os animais mais eficientes dentro de um sistema de produção (Lanna, 1997).

O desempenho de bovinos na fase de terminação, seu rendimento em carcaça e a qualidade de sua carne dependem da combinação dos fatores raça e alimentação. Ambos irão afetar a precocidade no acabamento do animal, que é determinante no rendimento e na qualidade da carcaça e da carne. Neste sentido, as diferenças na composição corporal dos animais implicam em exigências nutricionais diferentes, que irão influenciar no seu custo de terminação.

Segundo NRC (1984), a composição corporal afeta diretamente a eficiência de utilização de alimentos para ganho de peso vivo e para produção de carne comestível. Sendo assim, o conhecimento das exigências de energia e proteína para a mantença e para o ganho de peso vivo de bovinos é de grande importância para o balanceamento de rações de custo mínimo para os diferentes níveis de desempenho animal.

A composição corporal é influenciada diretamente pela raça do animal. Dentro de espécies, a quantidade de gordura e proteína, para um mesmo peso vivo, varia em função do tempo que as mesmas levam para atingir o tamanho maduro (Reid et al., 1980).

Entre as raças selecionadas para corte, ocorre uma diferença fundamental no porte dos animais, e, conseqüentemente, na composição corporal das raças britânicas em relação às continentais. É bem aceito que as raças zebuínas têm menores exigências de mantença em relação a raças britânicas e aos cruzamentos entre os dois grupos (Boin, 1995). As diferenças ocorridas nas exigências para mantença e para ganho de peso de animais do mesmo peso refletem as diferenças raciais, e estão intimamente relacionadas à composição do corpo vazi o do animal.

O ganho de peso vivo, entre raças ou sexos diferentes, depende fundamentalmente do nível de ingestão de energia. Porém, a ingestão de energia tem influência sobre o ganho de peso somente quando os outros nutrientes da dieta estão balanceados, principalmente a proteína (Reid et al., 1980). 
Alleoni et al. (1982), observaram que novilhos Caracu, confinados na fase de acabamento, apresentaram bom ganho de peso vivo diário, indicando bom potencial de crescimento a ser explorado para produção de carne. Alleoni et al. (1997b) não encontraram diferença significativa para peso vivo em confinamento entre animais Nelore e Caracu, mas os garrotes da raça Nelore apresentaram melhor conversão alimentar.

A determinação da composição corporal de bovinos é importante para a avaliação do desempenho animal e para a estimativa de suas exigências nutricionais. Os métodos diretos para a avaliação da composição corporal e da carcaça consistem na separação e na dissecação de todas as partes do corpo dos animais e determinação dos constituintes químicos e físicos (Hankins \& Howe, 1946). Entre os métodos indiretos, destaca-se a ultra-sonografia em tempo real, que possibilita a qualificação dos tecidos muscular e adiposo, através da análise de imagens coletadas de animais vivos (Simm, 1983).

Os abates seriados são uma técnica adequada para determinarem-se as exigências de mantença e de ganho de peso de bovinos em contínua alteração da composição corporal. Assim, no estudo referente ao efeito de determinada dieta sobre a composição corporal, um grupo de animais semelhantes é amostrado e abatido no início do experimento. Os outros animais são alimentados até pesos pré-determinados, abatidos e têm a sua composição corporal analisada. As diferenças observadas são devidas à aplicação dos diversos tratamentos (NRC, 1984).

Razook et al. (2001 a) comparando resultados do abate de animais Gir, Guzerá, Nelore seleção e controle, e Caracu, com idade média de 580 dias verificaram que o Nelore seleção e o Caracu apresentam maiores pesos ao abate que os Nelore controle. Não foram observadas diferenças em rendimento quente, grau de acabamento na carcaça, força de cisalhamento e perdas entre os dois grupos de Nelore. Em outro trabalho, Razook et al. (2001 b) obtiveram estimativas, baseadas em equações de regressão entre medidas feitas no corte da $9^{\mathrm{a}}-10^{\mathrm{a}}-11^{\mathrm{a}}$ costelas e a composição de carcaça daqueles animais e verificaram que não houve diferença significativa entre seleção e controle, quanto às proporções de músculo, gordura e ossos na carcaça. No entanto, estes 
autores sugerem a necessidade de estudos mais completos da composição integral das carcaças dos diferentes grupos genéticos do projeto.

Estudando a composição corporal de bovinos alimentados com diferentes rações, Ferreira et al. (2000) concluíram que os níveis de concentrado não afetaram os rendimentos dos cortes básicos, a área de olho de lombo, o rendimento, e as proporções de músculo e gordura da carcaça.

Já Gesualdi Jr. et al. (2000), estudando a influência de níveis de concentrado na dieta sobre características de carcaça, constataram que o rendimento, em relação ao peso vivo, aumentou linearmente, à medida que se elevou o nível de concentrado. Porém, não foram observadas alterações para os rendimentos de qualquer corte comercial da carcaça.

A composição dos diversos tecidos corporais e da carcaça influenciam os rendimentos e a qualidade da carne e possibilitam uma avaliação integral dos bovinos de corte. $\mathrm{O}$ interesse pela qualidade da carne consumida vem crescendo muito nos últimos tempos. Pode-se avaliar a carne pela sua maciez, cor e composição química. Existe uma preocupação dos consumidores por carnes com menor teor de gordura e padrões mais homogêneos de maciez. Assim, a indústria alimentícia deve dar ênfase às características de composição das carcaças, evitando gordura excessiva e maciez variável nos cortes cárneos (Nardon, 1998).

A seleção de animais para maior taxa de crescimento ou baixo conteúdo de gordura freqüentemente resulta num aumento do peso corporal adulto. Isto ocorre porque, a um determinado peso, animais com maior tamanho de esqueleto e maior peso adulto apresentam curva de crescimento antecipada, com menos lipídeos na massa corporal. Estes animais são mais eficientes na produção de músculo e têm teor reduzido de gordura a um determinado peso de abate (Owens et al., 1993).

Nardon (1998), estudando o efeito da seleção de bovinos sobre a composição corporal e as características de carcaça, constatou que os animais selecionados da raça Nelore consumiram mais alimentos, porém, tiveram carcaças mais pesadas e maior quantidade de porção comestível que os animais não selecionados. 
Alleoni et al. (1997a) constataram que novilhos Nelore apresentaram maiores rendimentos de carcaça e porcentagem de traseiro especial e menor porcentagem de dianteiro que animais da raça Caracu. Porém, os mesmos autores não observaram diferença significativa na produção de cortes cárneos da carcaça e do traseiro especial entre as duas raças.

Segundo Felício (1995), a carne ótima é aquela que apresenta coloração vermelho-cereja, quantidade ótima de gordura, um mínimo de suco exsudado, maciez, suculência, sabor, alto teor protéico, baixa caloria, ausência de patógenos e de resíduos químicos e baixa contagem de microrganismos deterioradores.

A maciez é considerada uma das mais importantes características sensoriais que afetam a palatabilidade da carne, embora a suculência e o sabor também tenham grande importância (Felício, 1995).

Os fatores que influenciam a qualidade da carne e sua maciez são a idade ao abate, a raça, o tipo de alimentação, o sexo, os tratamentos pós-morte, a qualidade e o tipo de colágeno, a glicose e a velocidade de resfriamento.

De maneira geral, a maciez está relacionada à idade do animal, mas o grau de acabamento tem influência no processo de resfriamento da carcaça, que, em determinados casos, pode causar o encurtamento excessivo da fibra muscular e, conseqüentemente, o endurecimento da carne pelo frio (Felício, 1995). 


\section{EFEITOS DA SELEÇÃO PARA PESO PÓS-DESMAME SOBRE CARACTERÍSTICAS DE CARCAÇA E RENDIMENTO DE CORTES CÁRNEOS COMERCIAS.}

\section{Resumo}

Quarenta e quatro machos inteiros provenientes dos rebanhos do projeto de melhoramento genético da Estação Experimental de Sertãozinho, selecionados ou não para peso aos 378 dias (P 378), nascidos em 1999, foram confinados na Estação Experimental de Colina. Foram utilizados animais dos grupos genéticos Nelore Seleção (NeS), Nelore Controle (NeC) e Caracu Seleção (Ca), os quais foram distribuídos aleatoriamente em duas categorias experimentais: grupo de alimentação restrita (AR) e grupo de alimentação Ad Libitum (AL). Em ambas categorias, foram alocados 8 animais dos grupos genéticos $\mathrm{NeS}$ e $\mathrm{Ca}$, e 6 animais do grupo $\mathrm{NeC}$. O período experimental foi determinado pelo tempo de acabamento dos animais, ou seja, quando os garrotes atingiram, no mínimo, 4,0 mm de espessura de gordura subcutânea, avaliada por ultrasom, sobre o músculo Longissimus dorsi, na posição entre a $12^{\mathrm{a}}$ e a $13^{\mathrm{a}}$ costelas. Em cada grupo genético, à medida que o acabamento preconizado para cada animal da categoria $\mathrm{AL}$ foi atingido, o animal da categoria $\mathrm{AR}$ mais semelhante àquele quanto ao peso e condição corporal, no início do experimento, foi também abatido. O efeito do grupo genético foi significativo para a maior parte das características estudadas, porém não houve interação significativa entre grupos genéticos e regimes alimentares. Os animais $\mathrm{Ca}$ e $\mathrm{NeS}$ tiveram maiores pesos de abate, porém requereram mais tempo de confinamento para atingirem o ponto de acabamento preconizado. O maior peso de abate destes animais também influenciou outras características correlacionadas, como peso da carcaça, traseiro, dianteiro e ponta de agulha. Verificoutse que a seleção para peso 
aumentou o peso de abate, de carcaça e de seus cortes primários, porém os animais selecionados apresentaram carne menos macia, mas ainda dentro dos padrões de maciez considerados bons.

Palavras-chave: bovinos, Caracu, carcaça, cortes básicos, maciez da carne, Nelore, seleção

\section{Summary}

Forty four bulls from Sertãozinho Experimental Station herds, selected or not for weight at 378 days (W 378), born in 1999, were feedlot at Colina Experimental Station. For this study animals of the genetic groups Nellore (NeS), Control Nellore $(\mathrm{NeC})$ and Caracu $(\mathrm{Ca})$ were utilized. They were randomnly distributed to the two experimental groups: restricted feeding group (AR) and Ad Libitum feeding group (AL).The groups had 8 animals $\mathrm{NeS}$ and $\mathrm{Ca}$, and 6 animals $\mathrm{NeC}$. Animals were slaughtered when the AL group reached $4,0 \mathrm{~mm}$ for ultrasonic fat thickness on Longissimus dorsi muscle, between the $12^{\text {th }}-13^{\text {th }}$ rib position. In each genetic group the animals were slaughtered in pairs. When an animal of the AL group reached the desired ultrasonic fat thickness, the animal of AR group that was similar in weight and body conditions score, at the experiment starting point, was also slaughtered. The genetic group effect was significative in the majority of traits studied, but there was not significative interaction between genetic groups and feeding groups. The $\mathrm{Ca}$ and $\mathrm{NeS}$ bulls were heavier at slaughter requiring longer feedlot period to reach the desired fat thickness. The higher slaughter weights of these animals also changed correlated traits as carcass, hindquater, forequarter and spare ribs weights. The selection for weight at 378 days of age in the Nellore resulted in heavier animals at slaughter, with $4.0 \mathrm{~mm}$ of fat thickness, heavier carcasses and its primary cuts, but selected animals had less tender meat.

Key-words: beef cattle, Caracu, carcass, meat tenderness, Nellore, prime cuts, selection 


\section{1 Introdução}

O sistema produtivo de carne bovina exige, cada vez mais, uma produção eficiente, em curto espaço de tempo, com produto de melhor qualidade, obtido pelo uso de animais geneticamente superiores, em condições ambientais adequadas.

O projeto de melhoramento genético da Estação Experimental de Zootecnia de Sertãozinho-SP (EEZS-SP) tem como objetivo principal o aumento da taxa de crescimento dos animais, por meio de seleção para peso pós-desmame. Além das mudanças nas características de crescimento, analisadas desde o início do programa de seleção, tornou-se fundamental o acompanhamento, também, das mudanças ocorridas nas características de qualidade da carne. Alguns estudos já publicados apresentam análises de características de carcaça envolvendo indivíduos dos rebanhos selecionados (Nardon et al., 1998; Resende et al., 2000; Resende et al., 2001).

Segundo Marshal (1994), características de composição de carcaça como peso, carne aproveitável, gordura aparada e ossos apresentam estimativas de herdabilidade, variando entre média e alta. Assim, a análise das características de carcaça de diferentes grupos genéticos torna-se interessante, já que estas são transmissíveis através das gerações.

As raças exploradas ou o manejo adotado influenciam o peso final de abate, a precocidade e o acabamento do animal. Algumas características importantes da carcaça, como a carne aproveitável, a cobertura de gordura, os subprodutos da desossa, maciez, entre outras, estão intimamente relacionadas à idade de abate do animal, ao seu grau de acabamento e ao peso de sua carcaça (Morris et al., 1993).

Os cortes básicos da carcaça de bovinos no mercado brasileiro são o dianteiro com cinco costelas, compreendendo o acém e a paleta completos, o costilhar ou ponta de agulha e o traseiro especial ou serrote, que inclui o coxão e a alcatra completa (Peron et al., 1993). Economicamente, seria desejável maior rendimento do traseiro especial, em relação a outros cortes, devido ao seu maior valor comercial.

O presente trabalho teve como objetivo dar continuidade às avaliações da carcaça e da qualidade da carne em grupos contemporâneos dos rebanhos Nelore e 
Caracu da EEZS-SP, selecionados para peso, e pertencentes à $19^{\text {a }}$ progênie destas linhas de seleção.

\subsection{Material e Métodos}

Os animais experimentais foram 44 machos inteiros provenientes dos rebanhos Nelore Seleção (NeS) e Caracu (Ca), selecionados para peso aos 378 dias de idade (P378), e Nelore Controle (NeC), animais não selecionados, da EEZS-SP. Estes animais, nascidos em 1999, participaram das Provas de Ganho de Peso (PGP) de 2000, segundo regras descritas por Razook et al. (1997). Ao final da PGP foram escolhidos 12 animais do grupo $\mathrm{NeC}$, e 16 dos $\mathrm{NeS}$ e $\mathrm{Ca}$, de modo a representar a média do peso padronizado aos 378 dias de cada rebanho.

A fase de confinamento foi realizada na Estação Experimental de Zootecnia de Colina. Os animais foram divididos em pares, de acordo com a semelhança na condição corporal. Dentro de cada par, foram sorteados dois regimes alimentares: $\mathrm{Ad}$ Libitum, onde os animais recebiam alimentação à vontade; e Restrito, onde foram fornecidas $65 \mathrm{~g} \mathrm{MS/} \mathrm{kg}$ de peso metabólico, procurando suprir suas exigências de mantença.

O período de adaptação teve duração de 28 dias, quando todos os animais receberam a ração utilizada na categoria Ad Libitum. Na entrada do período de adaptação do experimento, os animais foram pesados e tiveram suas condições corporais avaliadas via ultra-som e escore corporal. A pesagem e as medidas de ultra-som e escore corporal foram repetidas a cada 28 dias.

Em cada grupo genético, à medida que um animal do grupo Ad Libitum atingiu o acabamento preconizado (mínimo de $4 \mathrm{~mm}$ de espessura de gordura, medida pelo ultra-som, sobre o músculo Longissimus dorsi, na posição entre a $12^{\mathrm{a}}$ e a $13^{\mathrm{a}}$ costelas), este foi abatido juntamente com o seu par do grupo Restrito.

Os animais foram abatidos com uma idade média de 22 meses, e os pesos vivos médios de abate observados foram: NeS Ad Libitum - 526,8 kg, NeS Restrito 456,8 kg, NeC Ad Libitum - 445,0 kg, NeC Restrito - 406,0 kg, Ca Ad Libitum - 562,5 kg 
e Ca Restrito - 486,5 kg. O abate foi feito no Frigorífico Minerva, localizado na cidade de Barretos-SP, e obedeceu ao procedimento normal de um frigorífico sob inspeção federal.

As carcaças permaneceram em câmara de resfriamento a aproximadamente $2^{\circ} \mathrm{C}$ por 24 horas. As meias carcaças direitas resfriadas foram divididas em dianteiro (5 costelas), ponta de agulha e traseiro especial. Posteriormente, foram separadas nos seguintes cortes comerciais: contrafilé, filé mignon, alcatra, patinho, coxão-mole, coxão-duro, lagarto, capa e aba, paleta, pescoço, acém, peito, cupim, músculos e ponta de agulha desossada e aparada.

Após a separação, cada corte foi pesado individualmente. As aparas e ossos também foram pesados e registrados para seus respectivos cortes primários: dianteiro, ponta-de-agulha e traseiro especial.

Para análise qualitativa da carne, retiraram-se amostras (bifes de $2,5 \mathrm{~cm}$ de espessura) do músculo Longissimus dorsi, na altura da $12^{\text {a }}$ costela. Estas amostras foram embaladas a vácuo e congeladas. Posteriormente, transferiram-se as amostras para uma câmara de resfriamento, com temperatura aproximada de $2^{\circ} \mathrm{C}$, por 12 horas, até o momento das análises de maciez e perdas por cożmento. Os bifes foram assados em forno com temperatura aproximada de $170^{\circ} \mathrm{C}$, e o controle da temperatura das amostras foi feito por termômetros individuais, colocados no seu centro geométrico. Quando a temperatura interna atingiu $70^{\circ} \mathrm{C}$, as amostras foram retiradas do forno e mantidas em temperatura ambiente. Determinaram-se as perdas por evaporação e drenagem durante o cozimento. Foram retiradas 6 amostras cilíndricas de cada bife, no sentido das fibras musculares, com aproximadamente $13 \mathrm{~mm}$ de diâmetro, com o auxílio de um vazador manual. Determinou-se a força de cisalhamento com o aparelho Warner-Bratzler Shear Force, fabricado pela GR Eletrical Manufacturing Company, com capacidade para 25 $\mathrm{kg}$.

$\mathrm{O}$ delineamento experimental foi inteiramente casualizado, com arranjo fatorial $3 \times 2$, sendo três grupos genéticos $(\mathrm{Ca}, \mathrm{NeS}$ e $\mathrm{NeC})$ e dois regimes alimentares (Ad Libitum e Restrito). Usourse a análise de variância para testar os efeitos dos grupos genéticos, dos regimes alimentares e da interação. Para a comparação das médias dos 
grupos genéticos utilizou-se o teste de Tukey. Todas as análises estatísticas foram realizadas usando o PROC GLM do SAS (1999).

\subsection{Resultados e Discussão}

$\mathrm{Na}$ Tabela 1 encontram-se as médias observadas para tempo de confinamento, peso vivo ao abate, peso da meia carcaça direita resfriada, pesos dos cortes primários da carcaça e rendimentos dos cortes primários da carcaça. Os rendimentos médios da porção comestível, dos ossos e das aparas, na meia carcaça direita inteira e nas suas subdivisões primárias, ou seja, traseiro, dianteiro e ponta de agulha, encontram-se na Tabela 2. Na Tabela 3 são apresentados os pesos médios dos principais cortes desossados e aparados do traseiro, dianteiro e ponta de agulha. As características de qualidade de carne, as áreas de olho de lombo real e transformada para $100 \mathrm{~kg}$ de carcaça e a espessura de gordura encontram-se na Tabela 4. Para as características estudadas não houve interação significativa entre regime alimentar e grupo genético. Entretanto, os efeitos principais de regime alimentar e grupo genético foram significativos para todas características analisadas.

Algumas características analisadas, como tempo de confinamento, rendimentos de aparas, pesos de alguns cortes de traseiro e dianteiro, força de cisalhamento e espessura de gordura, apresentaram altos coeficientes de variação, indicando grandes variações nos dados usados para o cálculos das médias.

Os animais foram avaliados quanto às características de produção e qualidade de carne, porém, neste estudo, apenas as diferenças entre $\mathrm{NeS}$ e $\mathrm{NeC}$ podem ser consideradas consequiência de seleção, uma vez que ambos rebanhos foram originados da mesma população base. No rebanho $\mathrm{Ca}$, embora a seleção tenha iniciado simultaneamente, há diferenças raciais, as mais evidentes relacionadas ao tamanho. Os animais pertencentes ao grupo Ad Libitum, quando comparados aos do grupo Restrito, sempre apresentaram maiores médias, já que não sofreram restrição alimentar. As médias dos dois níveis de alimentação, para as diversas características estudadas, encontram-se nos anexos. 
Tabela 1. Médias dos tempos de confinamento (dias), dos pesos vivos ao abate (kg), dos pesos das meias carcaças direitas resfriadas $(\mathrm{kg})$ e dos pesos $(\mathrm{kg})$ e rendimentos $(\%)$ dos cortes primários

\begin{tabular}{|c|c|c|c|c|}
\hline & \multicolumn{3}{|c|}{ Rebanhos } & \multirow{2}{*}{$\begin{array}{l}\mathrm{CV} \\
(\%)\end{array}$} \\
\hline & $\mathrm{Ca}$ & $\mathrm{NeS}$ & $\mathrm{NeC}$ & \\
\hline Tempo de confinamento & $130 \mathrm{a}$ & $115 \mathrm{ab}$ & $104 \mathrm{~b}$ & 21,28 \\
\hline Peso vivo & $525,6 \mathrm{a}$ & 493,1 a & $424,3 \mathrm{~b}$ & 7,80 \\
\hline Peso carcaça direita & $149,5 \mathrm{a}$ & $143,7 \mathrm{a}$ & $124,6 \mathrm{~b}$ & 9,79 \\
\hline \multicolumn{5}{|l|}{ Quartos } \\
\hline Traseiro Especial & 66,11 a & 66,06 a & $58,10 \mathrm{~b}$ & 9,30 \\
\hline Dianteiro & $63,65 \mathrm{a}$ & 60,46 a & $52,15 \mathrm{~b}$ & 11,34 \\
\hline Ponta de Agulha & $19,37 \mathrm{a}$ & $17,08 \mathrm{~b}$ & $14,73 \mathrm{c}$ & 12,14 \\
\hline \multicolumn{5}{|l|}{ Rendimento dos Quartos } \\
\hline Traseiro Especial & $44,3 \mathrm{~b}$ & $46,1 \mathrm{a}$ & $46,7 \mathrm{a}$ & 3,09 \\
\hline Dianteiro & $42,6 \mathrm{a}$ & $42,0 \mathrm{a}$ & $41,4 \mathrm{a}$ & 3,91 \\
\hline Ponta da agulha & $12,9 \mathrm{a}$ & $11,8 \mathrm{~b}$ & $11,8 \mathrm{~b}$ & 5,90 \\
\hline
\end{tabular}

Animais $\mathrm{NeS}$ e $\mathrm{Ca}$ foram similares quanto ao peso de abate, quanto ao peso da carcaça direita e quanto ao tempo de confinamento, e superiores aos $\mathrm{NeC}$. Tais diferenças refletem-se nos quartos traseiro, dianteiro e ponta de agulha expressos em kg. Em termos de rendimento destas partes, observa-se que os animais Nelore são superiores aos Caracu quanto ao traseiro especial e apresentam menores valores de ponta de agulha. Relativamente ao dianteiro, os três grupos genéticos não diferem entre si.

Analisando as características de porção comestível, pode-se observar que não houve diferença significativa para os três grupos genéticos estudados. Para a porcentagem de ossos, não houve diferença significativa entre os grupos $\mathrm{NeS}$ e $\mathrm{NeC}$, para dianteiro e ponta de agulha. Os animais $\mathrm{Ca}$ possuem porcentagens de ossos semelhantes aos NeS. Na característica porcentagem de aparas não ocorreram diferenças significativas entre os três grupos genéticos. 
Tabela 2. Médias, em \%, da porção comestível, ossos e aparas, obtidos na meia carcaça direita dos bovinos, e em seus respectivos quartos

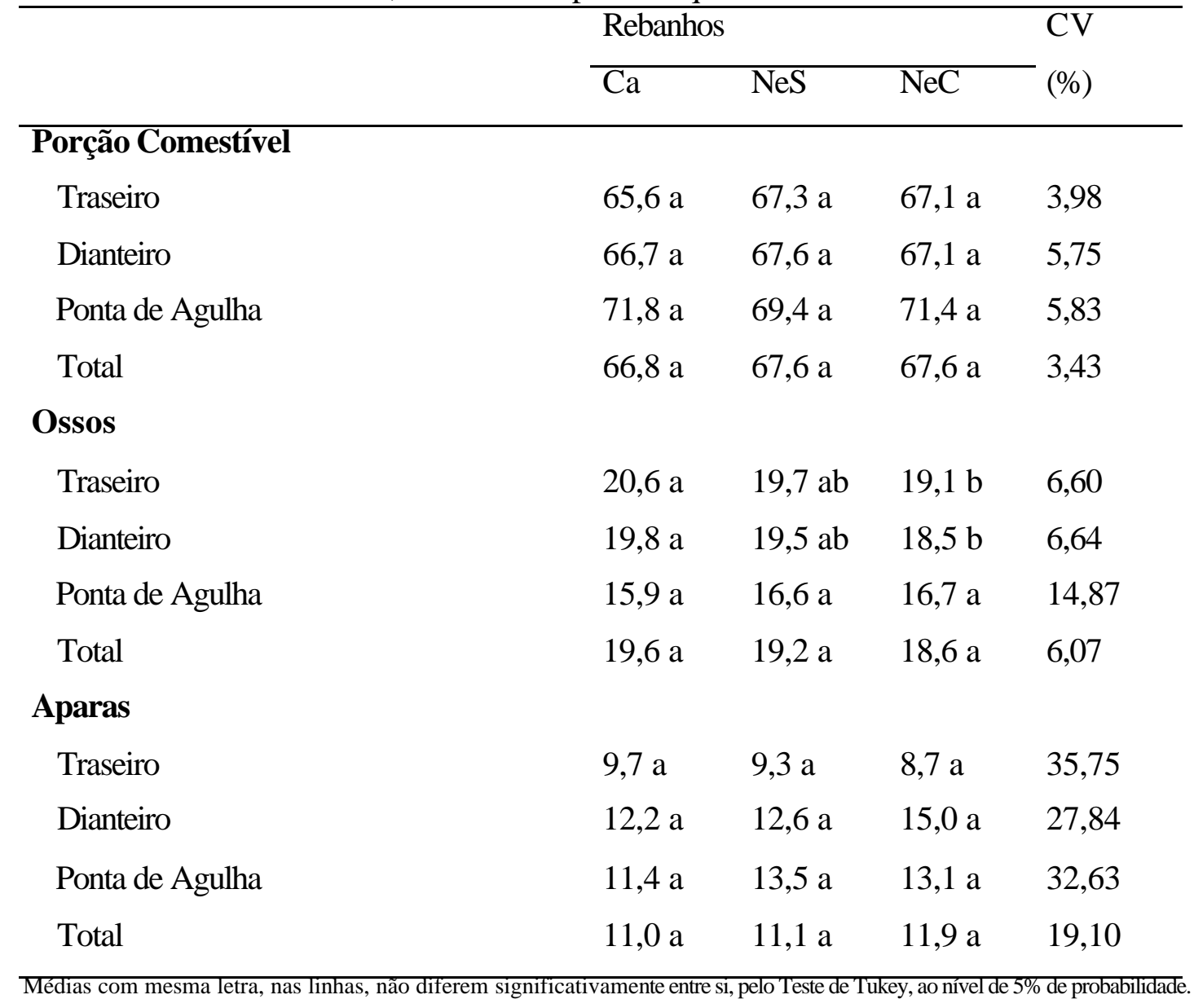

Comparando os grupos $\mathrm{NeS}$ e $\mathrm{NeC}$, observou-se que os valores de cortes aparados importantes do traseiro, como filé mignon, alcatra, patinho, coxão mole e lagarto foram maiores para os animais NeS. Os maiores valores nos cortes aparados dos animais selecionados foram influenciados pelo maior peso de carcaça. Em relação ao corte cupim, esperava-se um menor valor para o $\mathrm{NeC}$, quando comparado ao $\mathrm{NeS}$, fato que não ocorreu. Uma possível explicação para isso pode ser a linhagem de touros que transmitem maiores cupins. Nardon (1998), comparando animais $\mathrm{NeC}$ e $\mathrm{NeS}$ pertencentes aos rebanhos de Sertãozinho, também não encontrou diferenças significativas para o corte cupim. 
Tabela 3. Pesos médios dos cortes aparados, em kg, retirados da meia carcaça direita dos bovinos

\begin{tabular}{|c|c|c|c|c|}
\hline & \multicolumn{3}{|c|}{ Rebanhos } & \multirow{2}{*}{$\begin{array}{l}\text { CV } \\
(\%)\end{array}$} \\
\hline & $\mathrm{Ca}$ & $\mathrm{NeS}$ & $\mathrm{NeC}$ & \\
\hline \multicolumn{5}{|l|}{ Cortes do Traseiro } \\
\hline Contra Filé & $8,85 \mathrm{a}$ & $7,48 \mathrm{ab}$ & $6,66 \mathrm{~b}$ & 14,50 \\
\hline Filé Mignon & $2,23 \mathrm{a}$ & $2,00 \mathrm{~b}$ & $1,73 \mathrm{c}$ & 11,15 \\
\hline Alcatra & $5,96 \mathrm{ab}$ & $6,61 \mathrm{a}$ & $5,54 \mathrm{~b}$ & 11,75 \\
\hline Patinho & $4,89 \mathrm{~b}$ & $5,12 \mathrm{a}$ & $4,48 \mathrm{~b}$ & 11,16 \\
\hline Coxão Mole & $8,04 \mathrm{ab}$ & $8,91 \mathrm{a}$ & $7,72 \mathrm{~b}$ & 12,03 \\
\hline Coxão Duro & $4,92 \mathrm{a}$ & $5,49 \mathrm{a}$ & $4,97 \mathrm{a}$ & 14,72 \\
\hline Lagarto & $2,36 \mathrm{ab}$ & $2,55 \mathrm{a}$ & $2,27 \mathrm{~b}$ & 12,52 \\
\hline Capa e Aba & $1,24 \mathrm{a}$ & $1,36 \mathrm{a}$ & $1,29 \mathrm{a}$ & 24,89 \\
\hline Músculo & $4,12 \mathrm{a}$ & $4,07 \mathrm{a}$ & $3,43 \mathrm{~b}$ & 12,61 \\
\hline Frauda & $0,85 \mathrm{a}$ & $0,93 \mathrm{a}$ & $0,88 \mathrm{a}$ & 28,98 \\
\hline \multicolumn{5}{|c|}{ Cortes do Dianteiro } \\
\hline Paleta & $11,04 \mathrm{a}$ & $10,59 \mathrm{a}$ & $8,94 \mathrm{~b}$ & 14,15 \\
\hline Pescoço & $5,61 \mathrm{a}$ & $5,01 \mathrm{a}$ & $4,45 \mathrm{a}$ & 27,39 \\
\hline Acém & $13,22 \mathrm{a}$ & $9,97 \mathrm{~b}$ & $7,97 \mathrm{c}$ & 18,18 \\
\hline Peito & $8,12 \mathrm{a}$ & $7,08 \mathrm{ab}$ & $6,26 \mathrm{~b}$ & 18,01 \\
\hline Cupim & $0,73 \mathrm{~b}$ & $4,31 \mathrm{a}$ & $4,08 \mathrm{a}$ & 52,49 \\
\hline Músculos & $3,94 \mathrm{a}$ & $4,03 \mathrm{a}$ & $3,00 \mathrm{~b}$ & 19,84 \\
\hline \multicolumn{5}{|l|}{ Ponta de Agulha } \\
\hline Ponta de Agulha & $13,95 \mathrm{a}$ & $11,83 \mathrm{~b}$ & $10,48 \mathrm{~b}$ & 12,49 \\
\hline
\end{tabular}


Tabela 4. Força de cisalhamento (kg), perdas no cozimento (\%), área de olho de lombo 1 $\left(\mathrm{cm}^{2}\right)$, área de olho de lombo $2\left(\mathrm{~cm}^{2} / 100 \mathrm{~kg}\right.$ de carcaça) e espessura de gordura (mm), medidas no contra filé dos bovinos

\begin{tabular}{lllll}
\hline & \multicolumn{2}{l}{ Rebanhos } & CV \\
\cline { 2 - 4 } & $\mathrm{Ca}$ & $\mathrm{NeS}$ & $\mathrm{NeC}$ & $(\%)$ \\
\hline Força de cisalhamento & $3,06 \mathrm{a}$ & $4,25 \mathrm{~b}$ & $3,17 \mathrm{a}$ & 29,58 \\
Perdas no cozimento & $22,1 \mathrm{a}$ & $23,7 \mathrm{a}$ & $22,9 \mathrm{a}$ & 15,58 \\
Área de olho de lombo 1 & $76,94 \mathrm{a}$ & $65,94 \mathrm{~b}$ & $64,75 \mathrm{~b}$ & 11,42 \\
Área de olho de lombo 2 & $51,67 \mathrm{a}$ & $46,34 \mathrm{~b}$ & $52,21 \mathrm{a}$ & 11,69 \\
Espessura de gordura & $4,5 \mathrm{~b}$ & $5,8 \mathrm{a}$ & 6,6 a & 35,21 \\
Médias com mesma letra, nas linhas, não diferem significativamente entre si, pelo Teste de Tukey, ao nível de 5\% de probabilidade.
\end{tabular}

As diferenças significativas observadas entre $\mathrm{NeS}$ e $\mathrm{NeC}$ refletem mudança correlacionada nas características da carcaça como conseqüência da seleção para peso pós-desmame. O processo de seleção aplicado aos animais proporcionou mudança genética média estimada em 46,4 e $34,5 \mathrm{~kg}$ no peso aos 378 dias de idade (P378), respectivamente, para os Nelore e Guzerá selecionados, em 15 anos de progênies, comparados aos Nelore não selecionados (Razook et al., 1998). Conseqüentemente, os pesos de abate e de carcaça também refletiram estes efeitos, bem como as diferentes taxas de crescimento apresentadas pelos grupos genéticos durante o período de terminação.

Os animais $\mathrm{NeS}$ tiveram os quartos significativamente mais pesados, quando comparados aos $\mathrm{NeC}$. Esta superioridade está de acordo com o progresso genético da ordem de 1,1\% ao ano, mencionado por Razook et al. (1998).

Comparando-se os rebanhos $\mathrm{Ca}$ e $\mathrm{NeS}$, observou-se que os animais $\mathrm{Ca}$ apresentaram dianteiro (embora a diferença não tenha sido significativa) e ponta de agulha mais pesados. Para o frigorífico interessa, dentre outros fatores, carcaças mais pesadas, com maior rendimento de traseiro e de seus cortes básicos aparados.

Os valores semelhantes para rendimentos de aparas e de porção comestível, quando o grupo $\mathrm{NeS}$ é comparado ao $\mathrm{NeC}$ foram coerentes com as observações de Nour \& Thonney (1987) e de Owens et al (1993). Morris et al (1993) 
observaram diferenças significativas entre animais selecionados e controle nas características peso da porção comestível da carcaça, traseiro, dianteiro e peso dos ossos, porém, não observaram diferenças para o peso das aparas.

Norman \& Felício (1981), trabalhando com as raças Charolesa, Canchim, Nelore e Guzerá, observaram que entre as características estudadas, os animais das duas primeiras raças apresentaram menos aparas de gordura do que as Nelore e Guzerá, e que foram iguais ou melhores do que as raças zebuínas com relação à quantidade de porção comestível e produção de carne de primeira qualidade.

Os animais $\mathrm{Ca}$ foram bem semelhantes aos $\mathrm{NeS}$ quanto ao peso dos cortes. Diferenças significativas foram detectadas apenas para os cortes filé mignon, patinho, acém e ponta de agulha. No caso dos cortes filé mignon, acém e ponta de agulha, a superioridade dos animais Ca pode ser explicada pelo maior comprimento do animal. Para o corte patinho, o maior valor encontrado para os NeS pode ser explicado pela melhor conformação de pernil desse grupo, sendo comumente esperado que animais da raça Caracu apresentem, em geral, traseiro mais descarnado. Esses resultados são coerentes com os encontrados por Nardon (1998).

Houve influência dos grupos genéticos sobre força de cisalhamento. Alleoni et al (1997b) não encontraram diferenças significativas para força de cisalhamento, entre animais das raças Nelore e Caracu. Já Nardon et al (1998) encontraram valores menores de força de cisalhamento apenas para animais Caracu. $\mathrm{O}$ grupo NeS apresentou maior média para força de cisalhamento, o que indica uma carne menos macia. Apesar disto, o valor encontrado $(4,25 \mathrm{~kg})$ ainda é indicativo de uma carne macia. Segundo Leme et al. (2002), valores de força de cisalhamento inferiores a 4,5 kg são bem aceitos.

Para as características área de olho de lombo real e espessura de gordura não foram encontradas diferenças significativas entre os grupos $\mathrm{NeS}$ e $\mathrm{NeC}$. Quando a área de olho de lombo foi transformada para $100 \mathrm{~kg}$ de carcaça, os animais $\mathrm{NeS}$ apresentaram menores médias. Morris et al. (1993) não encontraram diferenças entre animais selecionados e não selecionados para as mesmas características. 
Os valores encontrados para estas características são bem próximos daqueles apresentados por Nardon (1998) e por Razook et al. (2001a), e abaixo dos mostrados por Luchiari Filho et al. (1989), para vários cruzamentos de vacas Nelore com touros de origem européia, e também por Alleoni et al. (1997b) para animais Caracu e Nelore de Sertãozinho.

A área de olho de lombo é um bom indicador da musculosidade da carcaça. Os animais $\mathrm{Ca}$, quando comparados aos $\mathrm{NeS}$ e $\mathrm{NeC}$, apresentaram maior média para essa característica, porém, quando a medida foi transformada para $100 \mathrm{~kg}$ de carcaça, a média dos animais Ca não diferiu da dos animais NeC. Nardon et al. (1997), em novilhos zebuímos com pesos médios de 423, 512 e $521 \mathrm{~kg}$, observaram área de olho de lombo de 61,3; 66,3 e 67,5 cm², respectivamente. Corte (1980) obtiveram área de olho de lombo de $81,4 \mathrm{~cm}^{2}$ para 1/2 Marchigiana: $1 / 2$ Nelore, $77,7 \mathrm{~cm}^{2}$ para os $1 / 2$ Chianina: $1 / 2$ Nelore e $67,1 \mathrm{~cm}^{2}$ para os Nelore. Esses valores demonstraram diferenças acentuadas entre zebuínos e raças de maior porte para a característica em questão.

Quanto à espessura de gordura, não foram encontradas diferenças entre os animais $\mathrm{NeS}$ e $\mathrm{NeC}$. Os animais $\mathrm{Ca}$ apresentaram menor espessura de gordura, quando comparados aos $\mathrm{NeS}$ e $\mathrm{NeC}$. Esse fato pode ser explicado pelo tamanho corporal dos animais $\mathrm{Ca}$, ou ainda pelas suas maiores exigências nutricionais. Uma das características das raças de grande porte é a baixa deposição de gordura (Luchiari Filho et al, 1985).

Os valores de espessura de gordura encontrados nesse estudo foram inferiores aos reportados por Nardon (1998), que variaram de 6 a 9,4 mm, porém muito acima das apresentadas por Jorge et al. (1997) para animais Gir, Guzerá, Nelore e Tabapuã.

Lunt (1985), comparando novilhos Aberdeen Angus, Brahman e cruzados Aberdeen Angus: Brahman, em diferentes períodos de confinamento, concluíram que os zebuínos tiveram deposição de gordura antecipada em relação aos outros genótipos. Esse fato também pode explicar o comportamento dos zebuínos $\mathrm{NeS}$ e $\mathrm{NeC}$, em relação aos Ca para a característica espessura de gordura. Em estudos comparativos de diferentes cruzamentos, Crouse et al (1989) concluíram que, quanto maior o grau de sangue zebuíno, menor a gordura intramuscular e maior a gordura de cobertura. 


\subsection{Conclusões}

Foram detectados efeitos da seleção para peso pós-desmame, nos animais Nelore e Caracu, sobre as características de carcaça, rendimento de cortes e qualidade da carne.

A seleção no Nelore tem levado a maiores pesos de abate e de carcaça, porém os animais selecionados exigiram mais tempo de confinamento para atingir o acabamento preconizado. Tais diferenças refletiram-se nos pesos dos quartos dianteiro e traseiro.

Os animais Caracu, quando comparados aos Nelore, apresentaram menor rendimento de traseiro, rendimento semelhante de dianteiro e maior rendimento de ponta de agulha.

Os bovinos do grupo Nelore selecionados para peso pós-desmame apresentaram maior valor para força de cisalhamento, indicando a possibilidade de produção de carne menos macia. Animais Caracu foram similares aos Nelore não selecionados quanto a força de cisalhamento. 


\section{EFEITO DA SELEÇÃo PARA PESO PÓS-DESMAME SOBRE A COMPOSIÇÃO CORPORAL DE BOVINOS.}

\section{Resumo}

Foi determinada a composição química corporal no peso vazio de 56 machos inteiros provenientes dos rebanhos do projeto de melhoramento genético da Estação Experimental de Sertãozinho, selecionados ou não para peso aos 378 dias (P 378), nascidos em 1999. Utilizaram-se animais dos grupos genéticos Nelore Seleção (NeS), Nelore Controle (NeC) e Caracu Seleção (Ca), os quais foram distribuídos aleatoriamente nas três categorias experimentais: grupo de abate inicial (AI), grupo de alimentação restrita (AR) e grupo de alimentação Ad Libitum (AL). Na categoria AI foram alocados 4 animais por grupo genético e nas categorias AR e AL foram alocados 8 animais $\mathrm{NeS}$ e Ca e 6 animais $\mathrm{NeC}$. Após o período de adaptação, a categoria AI foi abatida e as outras duas (AR e AL) entraram no ensaio de alimentação. Determinoutse o período experimental pelo tempo necessário para acabamento dos animais $\mathrm{AL}$, ou seja, quando os garrotes atingiram, no mínimo, 4,0 mm de espessura de gordura, avaliada por ultra-som, sobre o músculo Longissimus dorsi, na posição entre a $12^{\mathrm{a}}$ e a $13^{\mathrm{a}}$ costelas. Em cada grupo genético, à medida que o acabamento preconizado para cada animal da categoria $\mathrm{AL}$ foi atingido, o animal da categoria $\mathrm{AR}$ mais semelhante àquele quanto ao peso e condição corporal, no início do experimento, foi também abatido. O efeito do grupo genético foi significativo para a maior parte das características estudadas, porém não houve interação significativa entre grupos genéticos e regimes alimentares. Os valores médios para os componentes químicos do corpo vazio em porcentagem de água, gordura, proteína e cinzas foram: Ca $(60,4 ; 15,5 ; 19,7 ; 4,4)$, NeS $(58,2 ; 19,4 ; 17,8 ; 4,6)$ e $\mathrm{NeC}(57,4 ; 20,2 ; 18,3 ; 4,1)$. As taxas médias de ganho de peso vazio $(\mathrm{kg} / \mathrm{dia})$, água 
(g/dia), gordura $(\mathrm{g} / \mathrm{dia})$, proteína $(\mathrm{g} / \mathrm{dia})$, cinzas (g/dia) e energia (Mcal/dia) foram: $\mathrm{Ca}$ $(1,01 ; 409 ; 382 ; 150 ; 70 ; 4,45), \mathrm{NeS}(1,00 ; 355 ; 482 ; 113 ; 46 ; 5,19)$ e NeC $(0,91 ; 301 ;$ $457 ; 103 ; 52 ; 4,91)$. A composição química média do ganho do corpo vazio, em porcentagem de água, gordura, proteína, cinzas e energia (Mcal/dia) foi: Ca (40,1; 36,8; $15,2 ; 8,0 ; 4,32), \mathrm{NeS}(35,8 ; 48,1 ; 11,3 ; 4,8 ; 5,19)$ e $\mathrm{NeC}(32,7 ; 49,5 ; 12,0 ; 5,8 ; 5,36)$. A seleção para peso pós-desmame, visualizada na comparação entre os grupos Nelore, não promoveu alterações indiretas na composição corporal desses animais, porém aumentou o tamanho corporal dos mesmos, tornando-os um pouco mais tardios. Os animais $\mathrm{Ca}$, quando comparados aos Nelore, apresentaram porcentagens menores de gordura e maiores de proteína no corpo vazio, fato que pode ser explicado pelo maior tamanho corporal desses animais.

Palavras -chave: bovinos, Caracu, composição corporal, Nelore, seleção

\section{Summary}

The chemical body composition on empty body weight was estimated in a sample of 56 bulls, born in 1999, from Sertãozinho Experimental Station herds, selected or not for weight at 378 days of age (W 378). Animals of the genetic groups Nellore (NeS), Control Nellore $(\mathrm{NeC})$ and Caracu (Ca) were utilized. They were randomnly distributed to the three experimental classes: initial slaughter group (AI), restricted feeding group (AR) and Ad Libitum feeding group (AL). The AI class had 4 animals for each genetic group and the AR and AL classes had 8 animals $\mathrm{NeS}$ and $\mathrm{Ca}$, and 6 animals $\mathrm{NeC}$. When the adaptation period finished, the AI class was slaughtered and the other classes (AR and $\mathrm{AL}$ ) started the feeding period. Animals $\mathrm{AL}$ were slaughtered with a value of $4.0 \mathrm{~mm}$ for ultrasonic fat thickness, on Longissimus dorsi muscle, between the $12^{\text {th }}-13^{\text {th }}$ rib position. In each genetic group, when an animal of the $\mathrm{AL}$ class attained the desired ultrasonic fat thickness for slaughter, the animal of $\mathrm{AR}$ class, with similar weight and body conditions score, at the experiment starting point, was also slaughtered. The genetic group effect was significative in the majority of traits studied, but there was not significative interaction between genetic group and feeding 
group. Average values for chemical components of empty body weight, in percentages of water, fat, protein and ash were: $\mathrm{Ca}(60.4 ; 15.5 ; 19.7 ; 4.4), \mathrm{NeS}(58.2 ; 19.4 ; 17.8$; 4.6) and $\mathrm{NeC}(57.4 ; 20.2 ; 18.3 ; 4.1)$. The average rates of empty gain for body weight (kg/day), water (g/day), fat (g/day), protein (g/day), ash (g/day) and energy (Mcal/day) were: $\mathrm{Ca}(1.01 ; 409 ; 382 ; 150 ; 70 ; 4,45), \mathrm{NeS}(1.00 ; 355 ; 482 ; 113 ; 46 ; 5,19)$ and $\mathrm{NeC}$ $(0.91 ; 301 ; 457 ; 103 ; 52 ; 4,91)$. The average rates of empty body gain chemical composition, in percentages of water, fat, protein, ash and energy (Mcal/day) were: $\mathrm{Ca}$ (40.1; 36.8; 15.2; 8.0; 4.32), NeS (35.8; 48.1; 11.3; 4.8; 5.19) and $\mathrm{NeC}(32.7 ; 49.5 ; 12.0$; 5.8; 5.36). The selection for post-weaning weights, observed by comparing the two nellore groups, did not promote any change on body composition of these animals, but increased their body size, so they required longer feedlot periods. The animals of genetic group $\mathrm{Ca}$, when compared with Nellore, had less fat and more protein, in percentages of empty body. It must be ocurred because they have larger mature body size.

Key-words: beef cattle, body composition, Caracu, Nellore, selection

\section{1 Introdução}

A pecuária de corte busca maximizar, economicamente, o crescimento dos animais. A determinação da composição corporal é de grande importância em estudos de nutrição que avaliam alimentos ou o crescimento em si. Entretanto, o crescimento é produto de um complexo processo que envolve o ambiente e o potencial genético do animal.

A avaliação do crescimento, através apenas do ganho de peso, limita as conclusões obtidas, pois não leva em consideração a composição química do ganho de peso vazio. O estudo do crescimento em função da taxa de deposição dos constituintes corporais torna possível a utilização de modelos que simulam o desempenho do animal.

A composição química corporal refere-se às porcentagens de extrato etéreo, proteína, água e cinzas, independentemente dos tecidos onde estão presentes. A presença de carboidratos no corpo do animal é desconsiderada, pois seu teor é baixo e 
constante, ao redor de 0,7\% na matéria seca (Reid et al., 1968). Assim, no cálculo do teor de energia do corpo vazio são consideradas apenas proteína e gordura, multiplicadas respectivamente por 5,641 e 9,343 (Boin, 1995). Além disso, o corpo vazio do animal representa todos os seus tecidos, retirados os conteúdos do trato gastrintestinal e da bexiga e também a bílis (Lofgreen \& Garret, 1968), diferenciando-se consideravelmente da composição da carcaça ou da porção comestível da carcaça.

Para avaliar o desempenho e as exigências de zebuínos, vários experimentos foram desenvolvidos, utilizando-se animais Nelore inteiros (Lanna, 1988; Boin, 1995), castrados (Leme et al, 1994; Alleoni et al., 1997a), e novilhas (Lanna et al., 1999).

O projeto de melhoramento genético da Estação Experimental de Zootecnia de Sertãozinho-SP (EEZS-SP) tem como objetivo principal o aumento da taxa de crescimento dos animais, por meio de seleção para peso pós-desmame (Cyrillo et al, 2000; Cyrillo et al., 2001; Razook et al., 1994; Razook et al., 2001a; Razook et al., 2001b).

O presente trabalho teve como objetivo dar continuidade às avaliações de desempenho comparativo em grupos contemporâneos dos rebanhos Nelore e Caracu da EEZS-SP, selecionados para peso, e pertencentes à $19^{\text {a }}$ progênie destas linhas de seleção, e determinar a composição corporal e a taxa de deposição de constituintes químicos dos mesmos animais.

\subsection{Material e Métodos}

Os animais experimentais foram amostras retiradas da 19aㅡ progênie dos rebanhos Nelore Seleção e Caracu, pertencentes à Estação Experimental do Instituto de Zootecnia de Sertãozinho, submetidos à seleção com base no peso aos 378 dias de idade (P378), e do rebanho de Nelore Controle onde não foi feita a seleção para peso.

Os animais dos três grupos genéticos foram escolhidos ao término da Prova de Ganho de Peso (PGP) de 2000, segundo regras descritas por Razook et al 
(1997), com idade média de 12 meses, obedecendo à média do peso aos 378 dias (P378) de cada rebanho.

Os animais de cada grupo genético Nelore Seleção (NeS), Nelore Controle (NeC) e Caracu Seleção (Ca) foram distribuídos, aleatoriamente, nas três categorias experimentais: grupo abate inicial ou referência $(\mathrm{AI})$, grupo de alimentação restrita (AR) e grupo alimentação Ad Libitum (AL). Nos grupos AI foram alocados 4 animais por grupo genético e nos grupos $\mathrm{AR}$ e $\mathrm{AL}$ foram alocados 8 animais $\mathrm{NeS}$ e $\mathrm{Ca}$ e 6 animais $\mathrm{NeC}$, perfazendo um total de 56 animais.

A fase de confinamento foi realizada na Estação Experimental de Zootecnia de Colina. O período de adaptação teve a duração de 28 dias quando todos os animais receberam a ração utilizada na categoria Ad Libitum. Após esse período, os animais do grupo referência (AI) foram abatidos. As dietas foram balanceadas com silagem de milho, milho moído, farelo de algodão, uréia, rumensin e mistura mineral. Elas foram reajustadas, semanalmente, com base no consumo e na porcentagem de matéria seca do volumoso e do concentrado.

Após o período de adaptação, as categorias AR e AL entraram no ensaio de alimentação. Os animais foram divididos em pares, de acordo com a semelhança no peso e condição corporal. Dentro de cada par, sortearam-se dois regimes alimentares: $A d$ Libitum, em que os animais recebiam alimentação à vontade; e Restrito, onde foram fornecidas $65 \mathrm{~g} \mathrm{MS} / \mathrm{kg}$ de peso metabólico, procurando suprir suas exigências de mantença.

$\mathrm{Na}$ entrada do período de adaptação do experimento, os animais foram pesados e tiveram suas condições corporais avaliadas via ultra-som e escore corporal. Repetiram-se a pesagem e as medidas de ultra-som e escore corporal a cada 28 dias.

Em cada grupo genético, à medida que um anima 1 do grupo $\mathrm{AL}$ atingiu $\mathrm{o}$ acabamento preconizado (mínimo de $4 \mathrm{~mm}$ de espessura de gordura, medida pelo ultrasom, no músculo Longissimus dorsi, na posição entre a $12^{\mathrm{a}}$ e a $13^{\mathrm{a}}$ costelas), este foi abatido, juntamente com o seu par do grupo AR.

Os animais foram abatidos com idade média de 22 meses, e os pesos vivos médios de abate observados foram: NeS Ad Libitum - 526,8 kg, NeS Restrito - 
456,8 kg, NeC Ad Libitum - 445,0 kg, NeC Restrito - 406,0 kg, Ca Ad Libitum - 562,5 kg e Ca Restrito - 486,5 kg. O abate foi feito no Frigorífico Minerva, localizado na cidade de Barretos-SP, e obedeceu ao procedimento normal de um frigorífico sob inspeção federal, sendo que o sangue, o fígado, as vísceras e os outros órgãos foram coletados para pesagem. O peso do corpo vazio (PCVZ) foi determinado pela soma dos pesos da carcaça, sangue, cabeça, couro, patas, cauda, órgãos e vísceras vazias e limpas.

As meias carcaças foram separadas em quartos dianteiro e traseiro entre a $5^{\mathrm{a}}$ e a $6^{\mathrm{a}}$ costelas, pesadas e colocadas em câmara de resfamento a aproximadamente $2^{\circ} \mathrm{C}$ por 24 horas. Após o resfriamento, os quartos dianteiro e traseiro da meia carcaça esquerda foram separados em músculos e ossos. Após a separação, o tecido muscular e os ossos foram acondicionados em sacos plásticos e congelados. A metade esquerda do couro foi picada e resfriada.

A composição corporal dos animais foi feita pela técnica de determinação direta, através da moagem de todos os tecidos do animal. Os componentes para a moagem foram as metades esquerdas do couro, cabeça, patas e carcaça e todo o tecido gastrintestinal, outros órgãos e a gordura.

O couro foi moído após resfriamento. Os demais componentes congelados foram reduzidos a pedaços menores através de serragem. Durante esta operação, procurou-se evitar qualquer perda de tecido da amostra. O material serrado foi moído seguidas vezes, até ser reduzido ao estado pastoso, sendo retiradas quatro amostras de aproximadamente 50 gramas cada.

'Determinou-se a umidade através da liofilização das amostras, por aproximadamente 80 horas, tempo necessário para atingirem peso constante. Em seguida, as amostras foram reduzidas a pedaços menores e moídas em liquiidificador com gelo seco.

O extrato etéreo foi determinado pela extração com éter dietílico em recipientes de $350 \mathrm{ml}$ e balões de $500 \mathrm{ml}$ durante 15 horas, sendo colocadas quatro amostras de aproximadamente 2 gramas cada, embaladas em papel de filtro, sendo a quantidade de extrato etéreo calculada como perda de matéria seca da amostra. 
O teor de cinzas foi determinado através da queima do material em mufla a $600^{\circ} \mathrm{C}$ por 4 horas.

O teor de proteína bruta foi calculado como a diferença entre o peso total da amostra e as quantidades de água, extrato etéreo e matéria mineral.

O delineamento experimental foi inteiramente casualizado, com arranjo fatorial 3x2, sendo três grupos genéticos $(\mathrm{Ca}, \mathrm{NeS}$ e $\mathrm{NeC})$ e dois regimes alimentares (Ad Libitum e Restrito). A análise de variância foi usada para testar os efeitos dos grupos genéticos, dos regimes alimentares e da interação. Para a comparação das médias dos grupos genéticos utilizou-se o teste de Tukey. Realizaram-se todas as análises estatísticas , usando o PROC GLM do SAS (1999).

\subsection{Resultados e Discussão}

$\mathrm{Na}$ Tabela 5 encontram-se os tempos de confinamento, os pesos vazios inicial e final dos grupos genéticos estudados. Os resultados de composição química corporal ao abate e taxas de deposição estão apresentados nas Tabelas 6 e 7. A composição química corporal do ganho de peso ocorrido entre o final do período de adaptação e o abate é apresentada na Tabela 8. Para as características estudadas não houve interação significativa entre regime alimentar e grupo genético, com exceção da porcentagem de cinzas no corpo vazio e no ganho dos animais estudados. Entretanto, o efeito principal de regime alimentar e grupo genético foi significativo para a maioria das variáveis.

Neste estudo, apenas as diferenças entre $\mathrm{NeS}$ e $\mathrm{NeC}$ podem ser consideradas consequiência de seleção, uma vez que ambos rebanhos foram originados da mesma população base. No rebanho $\mathrm{Ca}$, embora a seleção tenha iniciado simultaneamente, há diferenças raciais, as mais evidentes relacionadas ao tamanho. 
Tabela 5. Tempos de confinamento (dias), pesos vazios inicial $(\mathrm{kg})$ e final $(\mathrm{kg})$ dos animais Caracu, Nelore Seleção e Nelore Controle

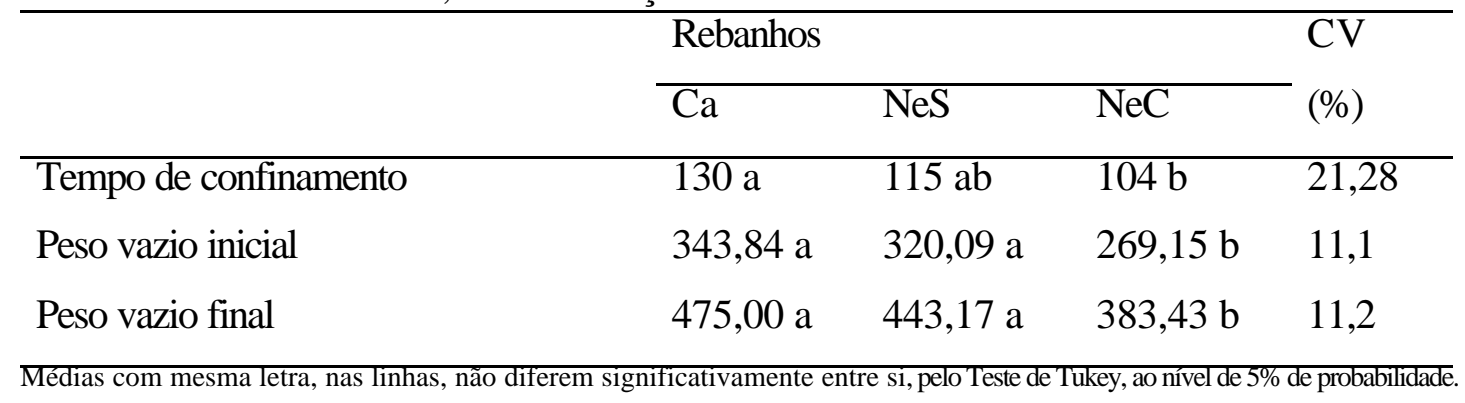

Os animais $\mathrm{NeC}$, por apresentarem menor tamanho corporal que os $\mathrm{NeS}$, alcançaram o acabamento de gordura preconizado em menor tempo e foram abatidos mais cedo. Por isso, apresentaram menores pesos vazios, tanto no início do experimento, como no final do período de confinamento. Não foram encontradas diferenças significativas entre os pesos vazios inicial e final dos grupos genéticos $\mathrm{NeS}$ e Ca.

Tabela 6. Taxas de ganho de peso vazio (kg/dia), dos constituintes químicos corporais (g/dia) e de energia (Mcal/dia) em animais Caracu, Nelore Seleção e Nelore Controle

\begin{tabular}{lllll}
\hline & \multicolumn{2}{l}{ Rebanhos } & $\mathrm{CV}$ \\
\cline { 2 - 3 } & $\mathrm{Ca}$ & $\mathrm{NeS}$ & $\mathrm{NeC}$ & $(\%)$ \\
\hline Ganho de peso vazio & $1,01 \mathrm{a}$ & $1,00 \mathrm{a}$ & $0,91 \mathrm{a}$ & 19,1 \\
Água & $409 \mathrm{a}$ & $355 \mathrm{a}$ & $301 \mathrm{a}$ & 33,3 \\
Gordura & $382 \mathrm{a}$ & $482 \mathrm{a}$ & $457 \mathrm{a}$ & 29,1 \\
Proteína & $150 \mathrm{a}$ & $113 \mathrm{ab}$ & $103 \mathrm{~b}$ & 40,0 \\
Cinza & $70 \mathrm{a}$ & $46 \mathrm{~b}$ & $52 \mathrm{ab}$ & 38,3 \\
Energia & $4,45 \mathrm{a}$ & $5,19 \mathrm{a}$ & $4,91 \mathrm{a}$ & 24,0 \\
\hline
\end{tabular}

Não houve diferença significativa para ganho de peso vazio nos três grupos genéticos. Animais Caracu depositaram menos gordura e mais proteína que os outros grupos genéticos, mas não foi detectada diferença significativa, devido ao alto coeficiente de variação para as características. 
Tabela 7. Composição do corpo vazio, em \%, dos animais Caracu, Nelore Seleção e Nelore Controle

\begin{tabular}{lllll}
\hline & \multicolumn{2}{l}{ Rebanhos } & \multicolumn{2}{c}{$\begin{array}{c}\text { NV } \\
\text { (\%) }\end{array}$} \\
\cline { 2 - 4 } & $\mathrm{Ca}$ & $\mathrm{NeS}$ & $\mathrm{NeC}$ & 3,0 \\
\hline Agua & $60,4 \mathrm{a}$ & $58,2 \mathrm{~b}$ & $57,4 \mathrm{~b}$ & 3,0 \\
Gordura & $15,5 \mathrm{~b}$ & $19,4 \mathrm{a}$ & $20,2 \mathrm{a}$ & 12,1 \\
Proteína & $19,7 \mathrm{a}$ & $17,8 \mathrm{~b}$ & $18,3 \mathrm{~b}$ & 5,6 \\
Cinza & $4,4 \mathrm{ab}$ & $4,6 \mathrm{a}$ & $4,1 \mathrm{~b}$ & 11,9 \\
Médias com mesma letra, nas linhas, não diferem significativamente entre si, pelo Teste de Tukey, ao nível de 5\% de probabilidade.
\end{tabular}

Quando comparados ao mesmo peso, animais de tamanho corporal pequeno apresentam maior teor de gordura e menor teor de proteína que animais de tamanho corporal grande. Conseqüentemente, animais de maior tamanho corporal têm menor exigência de energia e maior exigência de proteína por quilo de ganho durante a fase de crescimento. Ao serem comparadas as porcentagens de gordura e poteína no corpo vazio dos animais dos grupos genéticos estudados, observa-se que os animais $\mathrm{Ca}$ apresentaram menor quantidade de gordura e maior quantidade de proteína que os animais Nelore.

Tabela 8. Composição do ganho do corpo vazio, em constituintes químicos (\%) e energia (Mcal/dia), de animais Caracu, Nelore Seleção e Nelore Controle

\begin{tabular}{lllll}
\hline & \multicolumn{3}{l}{ Rebanhos } & $\mathrm{CV}$ \\
\cline { 2 - 4 } & $\mathrm{Ca}$ & $\mathrm{NeS}$ & $\mathrm{NeC}$ & $(\%)$ \\
\hline Água & $40,1 \mathrm{a}$ & $35,8 \mathrm{a}$ & $32,7 \mathrm{a}$ & 21,9 \\
Gordura & $36,8 \mathrm{~b}$ & $48,1 \mathrm{a}$ & $49,5 \mathrm{a}$ & 23,0 \\
Proteína & $15,2 \mathrm{a}$ & $11,3 \mathrm{a}$ & $12,0 \mathrm{a}$ & 38,6 \\
Cinza & $8,0 \mathrm{a}$ & $4,8 \mathrm{~b}$ & $5,8 \mathrm{ab}$ & 43,7 \\
Energia & $4,32 \mathrm{~b}$ & $5,19 \mathrm{a}$ & $5,36 \mathrm{a}$ & 16,4 \\
\hline Médias com mesma letra, nas linhas, não diferem significativamente entre si, pelo Teste de Tukey, ao nivel de 5\% de probabilidade.
\end{tabular}


A porcentagem de minerais encontrada no corpo vazio dos animais dos três grupos genéticos foi semelhante àquelas encontradas por Leme et al. (1994) e Alleoni et al. (1997a), que, trabalhando com animais Nelore, obtiveram 4,4 e 4,5\%, respectivamente. Esses autores encontraram no corpo vazio, teores de proteína de 17,9 e $17,1 \%$, e de extrato etéreo de 17,9 e $21,1 \%$, respectivamente. O teor de água foi semelhante ao encontrado por Leme et al. (1994), que obteve 59,6\%.

Trabalhando com tourinhos Santa Gertrudis, Berndt et al. (1999) observaram $42 \%$ de gordura no ganho de peso vazio. Essa elevada proporção de gordura pode ser explicada pelo uso de $80 \%$ de concentrado na dieta dos animais.

A composição corporal de animais Nelore, Nelore X Marchigiana e mestiços leiteiros com sangue Holandês foi estimada por Lanna et al. (1997). As porcentagens finais de gordura encontradas no corpo vazio foram 19, 16 e 18\% respectivamente. Os autores justificam os baixos teores de gordura em função de os animais serem machos inteiros, e estarem em crescimento compensatório, apesar de terem sido abatidos com pesos elevados (cerca de $500 \mathrm{~kg}$ ).

Bulle et al (2002) não encontraram efeito de raça ou tratamento na composição do ganho de peso vazio. Os animais britânicos apresentaram teores de $28,9 \%$ de gordura e 3,67 Mcal/kg de ganho de peso vazio, valores acima dos encontrados por Putrino (2002), que trabalhando com animais Brangus obteve 22,86\% de gordura e 2,99 Mcal/kg de ganho de peso vazio.

Jorge et al. (1999) forneceram alimentação Ad Libitum e restrita para tourinhos Gir, Guzerá, Tabapuã e Nelore. Não foram encontradas diferenças entre as raças para as concentrações corporais de proteína, gordura e energia. Os animais abatidos com maiores pesos corporais apresentaram menores porcentagens de proteína e maiores de gordura.

Ferrel \& Jenkins (1998) forneceram alimento Ad Libitum ou restrito a novilhos com diferentes combinações maternas e paternas. Os animais que receberam ração $A d$ Libitum foram mais pesados no momento do abate e apresentaram maiores quantidades de água, gordura, proteína, cinzas e energia do que os alimentados com 
restrição. As taxas de ganho dos componentes do corpo também foram maiores para os animais alimentados à vontade.

Tedeschi et al. (2002) trabalharam com animais Nelore inteiros e castrados alimentados Ad Libitum ou com 65\% do consumo Ad Libitum. Para os animais inteiros não foi encontrada diferença significativa entre os tratamentos para porcentagem de água $(61,9$ e $63,2 \%)$ e proteína $(17,5$ e 18,3\%) no ganho de peso vazio. Foram encontrados teores de proteína semelhantes aos obtidos por Putrino (2002) com tourinhos Nelore.

\subsection{Conclusões}

Embora a seleção para maior peso pós-desmame tenha determinado diferentes potenciais de crescimento dos animais, não houve grande alteração na composição corporal dos mesmos. Porém, os tempos de confinamento observados para atingir o acabamento preconizado foram diferentes.

Animais com maior tamanho corporal, como os Caracu, apresentaram mais proteína e menos gordura no corpo vazio que animais de tamanho intermediário, como os Nelore. 


\section{CONCLUSÕES GERAIS}

A seleção para peso pós-desmame, no Nelore, tem levado a maiores pesos de abate e de carcaça, porém, os animais selecionados exigiram mais tempo de confinamento para atingir o acabamento preconizado. Como consequência, foram evidenciadas diferenças na carcaça e no rendimento dos vários cortes. Animais Caracu, quando comparados aos Nelore, apresentaram menor rendimento de traseiro, rendimento semelhante de dianteiro e maior rendimento de ponta de agulha.

Os animais Nelore selecionados para peso pós-desmame apresentaram maior valor para força de cisalhamento, comparativamente aos Caracu e aos Nelore não selecionados, indicando a possibilidade de produção de carne menos macia.

A seleção para maior peso pós-desmame alterou o potencial de crescimento dos animais, porém, não promoveu grandes diferenças na composição corporal dos mesmos, ainda que terminados em regimes alimentares distintos. Os animais da raça Caracu, por apresentarem maiores tamanhos corporais que os Nelore, apresentaram mais proteína e menos gordura no corpo vazio. 


\section{ANEXOS}


Anexo A. Probabilidades (teste F) das causas de variação Grupo Genético (GG), Regime Alimentar (RA) e Interação GG x RA, referentes à Tabela 1

\begin{tabular}{lccc}
\hline & \multicolumn{3}{c}{ Efeito } \\
\cline { 2 - 4 } & Grupo & Regime & Interação \\
Genético & Alimentar & GG x RA \\
\hline Tempo de confinamento & 0,0310 & - & - \\
Peso vivo & $<, 0001$ & $<, 0001$ & 0,3540 \\
Peso carcaça direita & $<, 0001$ & $<, 0001$ & 0,6093 \\
Quartos & & & \\
Traseiro Especial & 0,0014 & 0,0002 & 0,6119 \\
Dianteiro & 0,0003 & 0,0001 & 0,8048 \\
Ponta de Agulha & $<, 0001$ & $<, 0001$ & 0,2518 \\
Rendimento dos Quartos & & & 0,9194 \\
Traseiro Especial & 0,0001 & 0,0206 & 0,7121 \\
Dianteiro & 0,1805 & 0,5230 & 0,1995 \\
Ponta de Agulha & 0,0002 & $<, 0001$ & \\
\hline
\end{tabular}


Anexo B. Probabilidades (teste F) das causas de variação Grupo Genético (GG), Regime Alimentar (RA) e Interação GG x RA, referentes à Tabela 2

\begin{tabular}{lccc}
\hline & \multicolumn{3}{c}{ Efeito } \\
\cline { 2 - 4 } & $\begin{array}{c}\text { Grupo } \\
\text { Genético }\end{array}$ & $\begin{array}{c}\text { Regime } \\
\text { Alimentar }\end{array}$ & $\begin{array}{c}\text { Interação } \\
\text { GG x RA }\end{array}$ \\
\hline Porção Comestível & 0,0108 & 0,0005 & 0,5791 \\
Traseiro & 0,8046 & 0,4354 & 0,8513 \\
Dianteiro & 0,2382 & 0,3934 & 0,5702 \\
Ponta de Agulha & 0,5160 & 0,1510 & 0,5087 \\
Total & & & \\
Ossos & 0,0131 & 0,0006 & 0,1592 \\
Traseiro & 0,0250 & $<, 0001$ & 0,2744 \\
Dianteiro & 0,6328 & 0,0267 & 0,0300 \\
Ponta de Agulha & 0,0670 & $<, 0001$ & 0,0763 \\
Total & & & \\
Aparas & 0,7470 & 0,4942 & 0,9690 \\
Traseiro & 0,1101 & 0,1757 & 0,6945 \\
Dianteiro & 0,3085 & 0,2408 & 0,1801 \\
Ponta de Agulha & 0,5614 & 0,0640 & 0,5721 \\
Total & & &
\end{tabular}


Anexo C. Probabilidades (teste F) das causas de variação Grupo Genético (GG), Regime Alimentar (RA) e Interação GG x RA, referentes à Tabela 3

\begin{tabular}{|c|c|c|c|}
\hline & \multicolumn{3}{|c|}{ Efeito } \\
\hline & Grupo & Regime & Interação \\
\hline & Genético & Alimentar & GG $\times$ RA \\
\hline \multicolumn{4}{|l|}{ Cortes do Traseiro } \\
\hline Contra Filé & $<, 0001$ & 0,0015 & 0,8745 \\
\hline Filé Mignon & $<, 0001$ & 0,0132 & 0,1611 \\
\hline Alcatra & 0,0012 & $<, 0001$ & 0,4744 \\
\hline Patinho & 0,0146 & 0,0007 & 0,4886 \\
\hline Coxão Mole & 0,0075 & 0,0039 & 0,2422 \\
\hline Coxão Duro & 0,0769 & 0,0094 & 0,7253 \\
\hline Lagarto & 0,0470 & 0,0001 & 0,5865 \\
\hline Capa e Aba & 0,5759 & 0,2783 & 0,5646 \\
\hline Músculo & 0,0012 & 0,0222 & 0,8185 \\
\hline Frauda & 0,7262 & 0,1545 & 0,4639 \\
\hline \multicolumn{4}{|c|}{ Cortes do Dianteiro } \\
\hline Paleta & 0,0017 & 0,0030 & 0,6057 \\
\hline Pescoço & 0,1047 & 0,0314 & 0,8716 \\
\hline Acém & $<, 0001$ & 0,0334 & 0,2547 \\
\hline Peito & 0,0023 & 0,0240 & 0,6548 \\
\hline Cupim & $<, 0001$ & 0,0016 & 0,5576 \\
\hline Músculos & 0,0015 & 0,2938 & 0,5205 \\
\hline \multicolumn{4}{|l|}{ Ponta de Agulha } \\
\hline Ponta de Agulha & $<, 0001$ & $<, 0001$ & 0,1022 \\
\hline
\end{tabular}


Anexo D. Probabilidades (teste F) das causas de variação Grupo Genético (GG), Regime Alimentar (RA) e Interação GG x RA, referentes à Tabela 4

\begin{tabular}{lccc}
\hline & \multicolumn{3}{c}{ Efeito } \\
\cline { 2 - 4 } & Grupo & Regime & Interação \\
& Genético & Alimentar & GG x RA \\
\hline Força de cisalhamento & 0,0049 & 0,5774 & 0,7462 \\
Perdas no cozimento & 0,4655 & 0,3910 & 0,3411 \\
Área de olho de lombo 1 & 0,0002 & 0,0026 & 0,4689 \\
Área de olho de lombo 2 & 0,0154 & 0,4574 & 0,6985 \\
Espessura de gordura & 0,0241 & 0,1400 & 0,5562 \\
\hline
\end{tabular}

Anexo E. Probabilidades (teste F) das causas de variação Grupo Genético (GG), Regime Alimentar (RA) e Interação GG x RA, referentes à Tabela 5

\begin{tabular}{lccc}
\hline & \multicolumn{3}{c}{ Efeitos } \\
\cline { 2 - 4 } & Grupo & Regime & Interação \\
& Genético & Alimentar & GG x RA \\
\hline Tempo de confinamento & 0,0310 & - & - \\
Peso vazio inicial & 0,0368 & - & - \\
Peso vazio final & $<, 0001$ & - & - \\
\hline
\end{tabular}


Anexo F. Probabilidades (teste F) das causas de variação Grupo Genético (GG), Regime Alimentar (RA) e Interação GG x RA, referentes à Tabela 6

\begin{tabular}{lccc}
\hline & \multicolumn{3}{c}{ Efeitos } \\
\cline { 2 - 4 } & $\begin{array}{c}\text { Grupo } \\
\text { Genético }\end{array}$ & $\begin{array}{c}\text { Regime } \\
\text { Alimentar }\end{array}$ & $\begin{array}{c}\text { Interação } \\
\text { GG x RA }\end{array}$ \\
\hline Ganho de peso vazio & 0,3558 & $<, 0001$ & 0,1485 \\
Água & 0,0722 & 0,0092 & 0,1958 \\
Gordura & 0,0854 & $<, 0001$ & 0,6377 \\
Proteína & 0,0340 & 0,0529 & 0,2972 \\
Cinza & 0,0100 & 0,8749 & 0,1363 \\
Energia & 0,2025 & $<, 0001$ & 0,4069 \\
\hline
\end{tabular}

Anexo G. Probabilidades (teste F) das causas de variação Grupo Genético (GG), Regime Alimentar (RA) e Interação GG x RA, referentes à Tabela 7

\begin{tabular}{lccc}
\hline & \multicolumn{3}{c}{ Efeitos } \\
\cline { 2 - 4 } & Grupo & Regime & Interação \\
Genético & Alimentar & GG x RA \\
\hline Água & 0,0001 & $<, 0001$ & 0,8570 \\
Gordura & $<, 0001$ & $<, 0001$ & 0,4543 \\
Proteína & $<, 0001$ & 0,0264 & 0,9058 \\
Cinza & 0,0518 & 0,0098 & 0,0135 \\
\hline
\end{tabular}


Anexo H. Probabilidades (teste F) das causas de variação Grupo Genético (GG), Regime Alimentar (RA) e Interação GG x RA, referentes à Tabela 8

\begin{tabular}{lccc}
\hline & \multicolumn{3}{c}{ Efeitos } \\
\cline { 2 - 4 } & $\begin{array}{c}\text { Grupo } \\
\text { Genético }\end{array}$ & $\begin{array}{c}\text { Regime } \\
\text { Alimentar }\end{array}$ & $\begin{array}{c}\text { Interação } \\
\text { GG x RA }\end{array}$ \\
\hline Agua & 0,0594 & 0,1703 & 0,6355 \\
Gordura & 0,0025 & 0,0280 & 0,8008 \\
Proteína & 0,0856 & 0,3925 & 0,9646 \\
Cinza & 0,0063 & 0,0069 & 0,0133 \\
Energia & 0,0024 & 0,0192 & 0,7778 \\
\hline
\end{tabular}


Anexo I. Pesos médios dos cortes cárneos aparados, retirados da meia carcaça direita dos bovinos e transformados para $100 \mathrm{~kg}$ de carcaça

\begin{tabular}{|c|c|c|c|c|}
\hline & \multicolumn{3}{|c|}{ Rebanhos } & \multirow{2}{*}{$\begin{array}{l}\mathrm{CV} \\
(\%)\end{array}$} \\
\hline & $\mathrm{Ca}$ & $\mathrm{NeS}$ & $\mathrm{NeC}$ & \\
\hline \multicolumn{5}{|l|}{ Cortes do Traseiro } \\
\hline Contra Filé & $5,91 \mathrm{a}$ & $5,20 \mathrm{~b}$ & $5,35 \mathrm{~b}$ & 9,01 \\
\hline Filé Mignon & $1,49 \mathrm{a}$ & $1,40 \mathrm{a}$ & $1,40 \mathrm{a}$ & 8,80 \\
\hline Alcatra & $3,98 \mathrm{~b}$ & $4,60 \mathrm{a}$ & $4,46 \mathrm{a}$ & 8,77 \\
\hline Patinho & $3,27 \mathrm{~b}$ & $3,57 \mathrm{a}$ & $3,61 \mathrm{a}$ & 6,39 \\
\hline Coxão Mole & $5,38 \mathrm{~b}$ & $6,21 \mathrm{a}$ & $6,20 \mathrm{a}$ & 7,24 \\
\hline Coxão Duro & $3,29 \mathrm{~b}$ & $3,81 \mathrm{a}$ & $4,00 \mathrm{a}$ & 9,96 \\
\hline Lagarto & $1,57 \mathrm{~b}$ & $1,78 \mathrm{a}$ & $1,82 \mathrm{a}$ & 6,98 \\
\hline Capa e Aba & $0,82 \mathrm{~b}$ & $0,94 \mathrm{ab}$ & $1,04 \mathrm{a}$ & 19,59 \\
\hline Músculo & $2,77 \mathrm{a}$ & $2,84 \mathrm{a}$ & $2,75 \mathrm{a}$ & 7,26 \\
\hline Frauda & $0,58 \mathrm{a}$ & $0,65 \mathrm{a}$ & $0,70 \mathrm{a}$ & 25,48 \\
\hline \multicolumn{5}{|c|}{ Cortes do Dianteiro } \\
\hline Paleta & $7,37 \mathrm{a}$ & $7,40 \mathrm{a}$ & $7,21 \mathrm{a}$ & 12,17 \\
\hline Pescoço & $3,75 \mathrm{a}$ & $3,49 \mathrm{a}$ & $3,50 \mathrm{a}$ & 24,33 \\
\hline Acém & $8,78 \mathrm{a}$ & $6,91 \mathrm{~b}$ & $6,44 \mathrm{~b}$ & 11,75 \\
\hline Peito & $5,41 \mathrm{a}$ & $4,91 \mathrm{a}$ & $5,03 \mathrm{a}$ & 12,39 \\
\hline Cupim & $0,46 \mathrm{~b}$ & $2,88 \mathrm{a}$ & $3,20 \mathrm{a}$ & 48,08 \\
\hline Músculos & $2,64 \mathrm{a}$ & $2,80 \mathrm{a}$ & $2,42 \mathrm{a}$ & 15,60 \\
\hline \multicolumn{5}{|l|}{ Ponta de Agulha } \\
\hline Ponta de Agulha & $9,27 \mathrm{a}$ & $8,22 \mathrm{~b}$ & $8,44 \mathrm{~b}$ & 8,36 \\
\hline
\end{tabular}


Anexo J. Médias dos tempos de confinamento (dias), dos pesos vivos ao abate (kg), dos pesos das meias carcaças direitas resfriadas $(\mathrm{kg})$, dos pesos $(\mathrm{kg})$ e rendimentos dos cortes primários, separando os dois níveis de alimentação

\begin{tabular}{lcccccc}
\hline & \multicolumn{2}{c}{$\mathrm{Ca}$} & \multicolumn{2}{c}{$\mathrm{NeS}$} & \multicolumn{2}{c}{$\mathrm{NeC}$} \\
\cline { 2 - 7 } & AL & AR & AL & AR & AL & AR \\
\hline Tempo de confinamento & 130 & 130 & 115 & 115 & 104 & 104 \\
Peso vivo & 565 & 486 & 529 & 458 & 443 & 405 \\
Peso carcaça direita & 160,9 & 138,0 & 155,0 & 132,4 & 131,3 & 117,8 \\
Quartos & & & & & & \\
Traseiro Especial & 70,63 & 61,60 & 70,41 & 61,70 & 60,53 & 55,67 \\
Dianteiro & 67,92 & 59,34 & 65,69 & 55,23 & 55,70 & 48,60 \\
Ponta de Agulha & 22,00 & 16,74 & 18,94 & 15,23 & 16,03 & 13,43 \\
Rendimento dos Quartos & & & & & & \\
Traseiro Especial & 43,9 & 44,7 & 45,5 & 46,7 & 46,2 & 47,3 \\
Dianteiro & 42,5 & 42,7 & 42,4 & 41,6 & 41,6 & 41,2 \\
Ponta de Agulha & 13,7 & 12,1 & 12,2 & 11,5 & 12,2 & 11,4 \\
\hline
\end{tabular}


Anexo K. Médias, em \%, da porção comestível, ossos e aparas, obtidos na meia carcaça direita dos bovinos, e em seus respectivos quartos, separando os dois níveis de alimentação

\begin{tabular}{lcccccc}
\hline & \multicolumn{2}{c}{ Ca } & \multicolumn{2}{c}{ NeS } & \multicolumn{2}{c}{ NeC } \\
\cline { 2 - 7 } & AL & AR & AL & AR & AL & AR \\
\hline Porção Comestível & & & & & & \\
$\quad$ Traseiro & 66,3 & 64,9 & 67,7 & 67,0 & 67,0 & 67,2 \\
Dianteiro & 67,5 & 65,8 & 68,1 & 67,1 & 67,1 & 67,1 \\
Ponta de Agulha & 73,2 & 70,5 & 69,2 & 69,6 & 71,9 & 70,9 \\
Total & 67,8 & 65,7 & 68,0 & 67,2 & 67,6 & 67,5 \\
Ossos & & & & & & \\
Traseiro & 19,4 & 21,8 & 18,9 & 20,5 & 18,9 & 19,3 \\
Dianteiro & 18,2 & 21,4 & 18,6 & 20,5 & 17,5 & 19,5 \\
Ponta de Agulha & 13,7 & 18,1 & 15,9 & 17,2 & 17,0 & 16,4 \\
Total & 18,1 & 21,1 & 18,4 & 20,1 & 18,1 & 19,0 \\
Aparas & & & & & & \\
Traseiro & 10,1 & 9,3 & 9,5 & 9,2 & 9,2 & 8,3 \\
Dianteiro & 13,5 & 10,8 & 13,4 & 11,9 & 15,2 & 14,8 \\
Ponta de Agulha & 13,8 & 9,1 & 13,9 & 13,4 & 12,7 & 13,4 \\
Total & 12,1 & 9,9 & 11,7 & 10,7 & 12,2 & 11,6 \\
\hline
\end{tabular}


Anexo L. Médias dos pesos dos cortes aparados, em kg, retirados da meia carcaça direita dos bovinos, separando os dois níveis de alimentação

\begin{tabular}{|c|c|c|c|c|c|c|}
\hline & \multicolumn{2}{|c|}{$\mathrm{Ca}$} & \multicolumn{2}{|c|}{$\mathrm{NeS}$} & \multicolumn{2}{|c|}{$\mathrm{NeC}$} \\
\hline & $\overline{\mathrm{AL}}$ & $\overline{\mathrm{AR}}$ & $\mathrm{AL}$ & $\overline{A R}$ & $\mathrm{AL}$ & $\overline{\mathrm{AR}}$ \\
\hline \multicolumn{7}{|l|}{ Cortes do Traseiro } \\
\hline Contra Filé & 9,56 & 8,15 & 8,05 & 6,91 & 7,15 & 6,17 \\
\hline Filé Mignon & 2,40 & 2,06 & 2,09 & 1,90 & 1,73 & 1,73 \\
\hline Alcatra & 6,58 & 5,33 & 7,14 & 6,07 & 5,84 & 5,24 \\
\hline Patinho & 5,29 & 4,49 & 5,48 & 4,76 & 4,65 & 4,32 \\
\hline Coxão Mole & 8,60 & 7,48 & 9,65 & 8,17 & 7,81 & 7,62 \\
\hline Coxão Duro & 5,29 & 4,55 & 5,89 & 5,09 & 5,15 & 4,79 \\
\hline Lagarto & 2,62 & 2,10 & 2,71 & 2,39 & 2,43 & 2,10 \\
\hline Capa e Aba & 1,36 & 1,11 & 1,37 & 1,34 & 1,32 & 1,27 \\
\hline Músculo & 4,29 & 3,95 & 4,32 & 3,83 & 3,56 & 3,31 \\
\hline Frauda & 0,85 & 0,87 & 1,03 & 0,83 & 0,96 & 0,80 \\
\hline \multicolumn{7}{|c|}{ Cortes do Dianteiro } \\
\hline Paleta & 12,01 & 10,07 & 11,33 & 9,85 & 9,34 & 8,53 \\
\hline Pescoço & 5,94 & 5,28 & 5,50 & 4,52 & 5,05 & 3,85 \\
\hline Acém & 14,34 & 12,10 & 10,86 & 9,07 & 7,90 & 8,05 \\
\hline Peito & 8,82 & 7,42 & 7,53 & 6,62 & 6,50 & 6,02 \\
\hline Cupim & 1,17 & 0,28 & 5,29 & 3,33 & 5,04 & 3,11 \\
\hline Músculos & 4,09 & 3,78 & 4,29 & 3,76 & 2,95 & 3,06 \\
\hline \multicolumn{7}{|l|}{ Ponta de Agulha } \\
\hline Ponta de Agulha & 16,12 & 11,79 & 13,07 & 10,59 & 11,47 & 9,49 \\
\hline
\end{tabular}


Anexo M. Médias de força de cisalhamento (kg), perdas no cozimento (\%), área de olho de lombo $1\left(\mathrm{~cm}^{2}\right)$, área de olho de lombo $2\left(\mathrm{~cm}^{2} / 100 \mathrm{~kg}\right.$ de carcaça) e espessura de gordura $(\mathrm{mm})$, medidas no contra filé dos bovinos, separando os dois níveis de alimentação

\begin{tabular}{lcccccc}
\hline & \multicolumn{2}{c}{$\mathrm{Ca}$} & \multicolumn{2}{c}{ NeS } & \multicolumn{2}{c}{$\mathrm{NeC}$} \\
\cline { 2 - 7 } & AL & AR & AL & AR & AL & AR \\
\hline Força de cisalhamento & 2,86 & 3,27 & 4,10 & 4,40 & 3,26 & 3,09 \\
Perdas no cozimento & 21,7 & 22,5 & 22,2 & 25,2 & 23,4 & 22,4 \\
Área de olho de lombo 1 & 82,88 & 71,00 & 68,63 & 63,25 & 67,83 & 61,67 \\
Área de olho de lombo 2 & 51,75 & 51,59 & 44,70 & 47,98 & 51,77 & 52,65 \\
Espessura de gordura & 5,4 & 3,7 & 5,9 & 5,7 & 7,0 & 6,2 \\
\hline
\end{tabular}

Anexo N. Composição corporal dos animais, em porcentagem, separando os níveis de alimentação

\begin{tabular}{lccccccccc}
\hline & \multicolumn{3}{c}{$\mathrm{Ca}$} & \multicolumn{3}{c}{$\mathrm{NeS}$} & \multicolumn{3}{c}{$\mathrm{NeC}$} \\
\cline { 2 - 9 } & AI & AL & AR & AI & AL & AR & AI & AL & AR \\
\hline Agua & 66,4 & 59,2 & 61,7 & 64,5 & 57,2 & 59,2 & 64,6 & 56,2 & 58,7 \\
Gordura & 7,9 & 17,8 & 13,1 & 9,8 & 20,8 & 18,0 & 10,8 & 21,7 & 18,6 \\
Proteína & 20,9 & 19,2 & 20,1 & 19,6 & 17,5 & 18,1 & 20,2 & 18,0 & 18,6 \\
Cinzas & 3,4 & 3,9 & 5,0 & 4,4 & 4,5 & 4,7 & 3,5 & 4,1 & 4,1 \\
\hline
\end{tabular}


Anexo O. Taxas de ganho dos diferentes componentes químicos dos animais, separando os dois níveis de alimentação

\begin{tabular}{lcccccc}
\hline & \multicolumn{2}{c}{$\mathrm{Ca}$} & \multicolumn{2}{c}{$\mathrm{NeS}$} & \multicolumn{2}{c}{$\mathrm{NeC}$} \\
\cline { 2 - 7 } & $\mathrm{AL}$ & $\mathrm{AR}$ & $\mathrm{AL}$ & $\mathrm{AR}$ & $\mathrm{AL}$ & $\mathrm{AR}$ \\
\hline Ganho peso vazio & 1,26 & 0,76 & 1,15 & 0,84 & 1,03 & 0,80 \\
Água & 504 & 314 & 397 & 313 & 314 & 288 \\
Gordura & 518 & 247 & 583 & 381 & 551 & 364 \\
Proteína & 181 & 120 & 126 & 100 & 105 & 102 \\
Cinzas & 60 & 80 & 49 & 44 & 57 & 46 \\
Energia & 5,90 & 2,99 & 6,22 & 4,17 & 5,81 & 4,01 \\
\hline
\end{tabular}

Anexo P. Composição do ganho do corpo vazio, em constituintes químicos (\%) e energia (Mcal/dia), dos animais, separando os dois níveis de alimentação

\begin{tabular}{lcccccc}
\hline & \multicolumn{2}{c}{$\mathrm{Ca}$} & \multicolumn{2}{c}{$\mathrm{NeS}$} & \multicolumn{2}{c}{$\mathrm{NeC}$} \\
\cline { 2 - 7 } & $\mathrm{AL}$ & $\mathrm{AR}$ & $\mathrm{AL}$ & $\mathrm{AR}$ & $\mathrm{AL}$ & $\mathrm{AR}$ \\
\hline Água & 39,6 & 40,6 & 34,6 & 37,0 & 29,3 & 36,1 \\
Gordura & 41,1 & 32,5 & 50,2 & 46,0 & 53,7 & 45,3 \\
Proteína & 14,3 & 16,0 & 10,9 & 11,7 & 11,2 & 12,8 \\
Cinzas & 5,0 & 10,9 & 4,2 & 5,3 & 5,8 & 5,8 \\
Energia & 4,68 & 3,95 & 6,22 & 5,37 & 5,00 & 5,00 \\
\hline
\end{tabular}




\section{REFERÊNCIAS BIBLIOGRÁFICAS}

ALLEONI, G. F.; BOIN, C.; TROVO, J. B. F. et al. Digestibilidade de alimentos e ganho de peso vivo com novilhos da raça Caracu. Zootecnia, v.20, n.2, p.121-135, 1982.

ALLEONI, G. F.; LEME, P. R.; BOIN, C. et al. Métodos indiretos para estimar a composição química da carcaça de novilhos Nelore. 2. Cortes da costela. In: REUNIÃO ANUAL DA SOCIEDADE BRASILEIRA DE ZOOTECNIA, 34., Juiz de Fora, 1997. Anais. Juiz de Fora: SBZ, 1997a. p. 320-322.

ALLEONI, G. F.; LUCHIARI FILHO, A.; BOIN, C. et al. Características de carcaça e desempenho em confinamento de novilhos Caracu comparados com novilhos Nelore. Ars Veterinária, v.13, n.2, p.141-149, 1997 b.

BERNDT, A.; LANNA, D. P. D.; LEME, P. R. et al. Milho úmido, bagaço de cana e silagem de milho em dietas de alto concentrado. 2. Composição corporal e taxas de deposição dos tecidos. In: REUNIÃO ANUAL DA SOCIEDADE BRASILEIRA DE ZOOTECNIA, 36., Porto Alegre, 1999. Anais. Porto Alegre: SBZ, 1999. p. 285.

BOIN, C. Alguns dados sobre exigências de energia e de proteína de zebuínos. In: SIMPÓSIO INTERNACIONAL SOBRE EXIGÊNCIAS NUTRICIONAIS DE RUMINANTES, 1., Viçosa, 1995. Anais. Viçosa: UFV, 1995. p. 457-465.

BULLE, M. L. M.; RIBEIRO, F. G.; LEME, P. R et al. Exigências líquidas de energia e proteína de tourinhos de dois grupos genéticos alimentados com dietas de alto teor de concentrado. Revista Brasileira de Zootecnia, v.31, n.1, p.436-443, 2002.

CORTE, O. O. Composição e qualidade de carne de tourinhos Nelore, Nelore-Chianina e Nelore-Marchigiana. Boletim Técnico ITAL, v.5, p. 1-10, 1980. 
CROUSE, J. D.; CUNDIFF, R. M.; KOCH, M. et al. Comparisons of Bos indicus and Bos taurus inheritance for carcass beef characteristics and meat palatability. Journal of Animal Science, v.67, n.5, p.2661-2668, 1989.

CYRILLO, J. N. S. G.; RAZOOK, A. G.; FIGUEIREDO, L. A. et al. Efeitos da seleção para peso pós desmame sobre medidas corporais e perímetro escrotal de machos Nelore de Sertãozinho. Revista Brasileira de Zootecnia, v.29, n.2, p.403-412, 2000.

CYRILlO, J. N. S. G.; RAZOOK, A. G.; FIGUEIREDO, L. A. et al. Estimativas de tendências e parâmetros genéticos do peso padronizado aos 378 dias de idade, medidas corporais e perímetro escrotal de machos Nelore de Sertãozinho, SP. Revista Brasileira de Zootecnia, v.30, n.1, p.56-65, 2001.

FELÍCIO, P. E. Maciez da carne: fator competitividade. DBO Rural, v.174, p.88-91, 1995.

FERREIRA, M. A.; VALADARES FILHO, S. C.; MUNIZ, E. B. et al. Características das carcaças, biometria do trato gastrintestinal, tamanho dos órgãos internos e conteúdo gastrintestinal de bovinos F1 Simental x Nelore alimentados com dietas contendo vários níveis de concentrado. Revista Brasileira de Zootecnia, v.29, n.4, p.1174-1182, 2000.

FERREL, C. L.; JENKINS, T. G. Body composition and energy utilization by steers of diverse genotypes fed a high-concentrate diet during the finish period: I Angus, Belgian Bleu, Hereford and Piedmontese Sires. Journal of Animal Science, v.76, n.2, p.637-646, 1998.

GESUALDI Jr., A.; PAULINO, M. F.; VALADARES FILHO, S. C. et al. Níveis de concentrado na dieta de novilhos F1 Limousin x Nelore: características de carcaça. Revista Brasileira de Zootecnia, v.29, n.5, p.1467-1473, 2000.

HANKINS,O. G.; HOWE, P. E. Estimation of the composition of beef carcasses and cuts. (USDA. Technical Bulletin, 926). Washington: USDA, 1946.

JORGE, A. M.; FONTES, C. A. A.; PAULINO, M. F. Efeito da raça e do nível nutricional sobre o tamanho dos órgãos internos em zebuínos. In: REUNIÃO ANUAL DA SOCIEDADE BRASILEIRA DE ZOOTECNIA, 34., Juiz de Fora, 1997. Anais. Juiz de Fora: SBZ, 1997. p. 466-468. 
JORGE, A. M.; FONTES, C. A. A.; PAULINO, M. F. Composição corporal de bovinos de quatro raças zebuínas, abatidos em diferentes estádios de maturidade. Revista Brasileira de Zootecnia, v.28, n.2, p.388-394, 1999.

LANNA, D. P. Estimativa da composição química do corpo vazio de tourinhos Nelore através da gravidade especificada carcaça e da composição de cortes das costelas. Piracicaba, 1988. 131 p. Dissertação (Mestrado)-Escola Superior de Agricultura "Luiz de Queiroz", Universidade de São Paulo.

LANNA, D. P. Fatores condicionantes e predisponentes da puberdade e da idade de abate. In: SIMPÓSIO SOBRE PECUÁRIA DE CORTE, 4., Piracicaba, 1997. Anais. Piracicaba: ESALQ, 1997. p. 79-97.

LANNA, D. P.; PACKER, I. U. Eficiência biológica e econômica de bovinos de corte. In: WORKSHOP SOBRE QUALIDADE DA CARNE E MELHORAMENTO GENÉTICO DE BOVINO DE CORTE, São Carlos, 1998. Anais. São Carlos: 1998. p. 83-104.

LANNA, D. P. L.; LEME, P. R.; BOIN, C. et al. Ganho compensatório de bovinos de diferentes grupos genéticos: composição química e física corporal. In: REUNIÃO ANUAL DA SOCIEDADE BRASILEIRA DE ZOOTECNIA, 34., Juiz de Fora, 1997. Anais. Juiz de Fora: SBZ, 1997. p. 352-354.

LANNA, D. P. L.; MORAIS, J. P.; BOIN, C. et al. Desempenho e composição corporal de novilhas alimentadas com dois níveis de concentrado e bagaço de cana submetido a diferentes processos de hidrólise. Revista Brasileira de Zootecnia, v.28, n.2, p.412-420, 1999.

LEME, P. R.; BOIN, C.; ALLEONI, G. F. et al. Estimativa da composição química corporal de novilhos Nelore através do espaço de deutério. Revista da Sociedade Brasileira de Zootecnia, v.26, n.3, p.351-362, 1994.

LEME, P. R.; SILVA, S.L.; PEREIRA, A. S. C. et al. Desempenho e características de carcaça de animais Nelore, $1 /$ Caracu x $1 / 2$ elore e $3 /$ Caracu x 1/4 Nelore confinados com dietas de alto concentrado. (compact disc). In: REUNIÃO ANUAL DA SOCIEDADE BRASILEIRA DE ZOOTECNIA, 39., Recife, 2002. SBZ 2002. trabalhos. Recife: SBZ, 2002. 
LOFGREEN, G. P.; GARRET, W. N. A system for expressing net energy requeriments and feed values for growing and finish beef cattle. Journal of Animal Science, v.27, n.3, p.793-806, 1968.

LUCHIARI FILHO, A.; BOIN, C.; ALLEONI, G. F. et al. Efeitos do tipo de animal no rendimento da porção comestível da carcaça. 1. Machos da raça Nelore vs cruzados zebu x europeu terminados em confinamento. Boletim de Indústria Animal, v.42, n.1, p.31-39, 1985.

LUCHIARI FILHO, A.; LEME, P. R.; RAZOOK, A. G. et al. Características de carcaça e rendimento da porção comestível da carcaça de machos Nelore comparadas a cruzados (F1) obtidos do acasalamento de touros das raças Canchim, Santa Gertrudis, Caracu, Holandês e Suíço com fêmeas Nelore. 1. Animais inteiros terminados em confinamento. Boletim de Indústria Animal, v.46, n.1, p.17-25, 1989.

LUNT, D. K. Carcass characteristics and composition of Brahman, Angus and Brahman steers fed for different times on feed. Meat Science, v.14, p. 137-152, 1985.

MARSHAL, D. M. Breed diferences and genetic parameters for body composition traits in beef cattle. Journal of Animal Science, v.72, n.10, p.2745-2755, 1994.

MERCADANTE, M. E. Z.; PACKER, I. U.; RAZOOK, A. G. et al. Dias ao parto de fêmeas Nelore de um experimento de seleção para crescimento de seleção para crescimento. I- Modelo de repetibilidade. Revista Brasileira de Zootecnia, v.31, n.4, p.1715-1725, 2002a.

MERCADANTE, M. E. Z.; PACKER, I. U.; RAZOOK, A. G. et al. Dias ao parto de fêmeas Nelore de um experimento de seleção para crescimento de seleção para crescimento. II- Modelo de regressão aleatória. Revista Brasileira de Zootecnia, v.31, n.4, p.1726-1733, 2002b.

MERCADANTE, M. E. Z.; PACKER, I. U.; RAZOOK, A. G. et al. Direct and correlated responses to selection for yearling weight on reproductive performance of Nelore cows. Journal of Animal Science, v.81, n.2. p.376-384, 2003. 
MORRIS, C. A.; BAKER, R. L.; BASS, J. J. et al. Carcass composition in weightselected and control bulls from a serial slaughter experiment. Australian Journal of Agricultural Research, v.44, n.2, p.199-213, 1993.

NARDON, R. F. Seleção de bovinos para desempenho: composição corporal e características de carcaça. Jaboticabal, 1998. 107 p. Tese (Doutorado)-Faculdade de Ciências Agrárias e Veterinárias, Universidade Estadual Paulista "Júlio Mesquita Filho).

NARDON, R. F.; TEDESCHI, L. O.; BOIN, C. et al. Características e composição de carcaças de zebuínos com diferentes índices de desempenho em provas de ganho de peso. In: REUNIÃO ANUAL DA SOCIEDADE BRASILEIRA DE ZOOTECNIA, 34., Juiz de Fora, 1997. Anais. Juiz de Fora: SBZ, 1997. p.343-345.

NARDON, R. F.; RAZOOK, A.G.; SAMPAIO, A. A. M. et al. Efeito da seleção para peso pós-desmama e de raças no rendimento de cortes da carcaça e na qualidade da carne de bovinos. (compact disc). In: REUNIÃO ANUAL DA SOCIEDADE BRASILEIRA DE ZOOTECNIA, 35., Botucatu, 1998. SBZ 1998: trabalhos. Botucatu: SBZ, 1998.

NORMAN, G. A.; FELÍCIO, P. E. Effects of breed and nutrition on the productive traits of zebu, Charolais and crossbreed beef cattle in south-east Brazil. 1. Body and gross carcass composition. Meat Science, v.5, p.425-438, 1981.

NOUR, A. Y. M.; THONNEY, M. L. Carcass, soft tissue and bone composition of early and late maturig steers fed two diets in two housing types and serially slaughtered over a wide weight range. Journal of Animal Science, v.64, n.3, p.1345-1355, 1987.

NRC. Nutrient requeriments of beef cattle. Washington: National Academy Press, 1984. 90p.

OWENS, F. N.; DUBESKI, P.; HANSON, C.F. Factors that alter the growth and development of ruminants. Journal of Animal Science, v.71, n.11, p.3138-3150, 1993. 
PACKER, I. U.; RAZOOK, A. G.; TROVO, J. B. F. Selection for yearling weigth in

Nelore and Guzerá zebu breeds: selection applied and response. In: INTRODUCTION BREEDING PROGRAMS FOR DAIRY AND BEEF CATTLE, SHEEP AND GOATS, WATER BUFFALO, 9.; WORLD CONGRESS ON GENETICS APPLIED TO LIVESTOCK PRODUCTION, 3., Lincoln, 1986. Proceedings. Lincoln: NSW, 1986. p. 419-423.

PERON, J. A.; FONTES, C. A. A.; LANA, R. P. et al. Rendimento de carcaça e de seus cortes básicos e área corporal de bovinos de cinco grupos genéticos submetidos à alimentação restrita e "ad libitum". Revista da Sociedade Brasileira de Zootecnia, v. 22, n.2, p.239-247, 1993.

PUTRINO, S. M. Exigências de proteína e energia líquidas para o ganho de peso de tourinhos das raças Nelore e Brangus alimentados com dietas com diferentes proporções de concentrado. Pirassununga, 2002. 82 p. Dissertação (Mestrado)Faculdade de Zootecnia e Engenharia de Alimentos, Universidade de São Paulo.

RAZOOK, A. G.; FIGUEIREDO, L. A.; BONILHA NETO, L.M. Diferenças observadas em progênies de touros Nelore testados em prova de ganho de peso e com diferenciais de seleção nulo ou positivo para o peso pós desmama, em um rebanho PO. Boletim de Indústria Animal, v.51, n.1, p.87-98, 1994.

RAZOOK, A. G.; FIGUEIREDO, L. A.; BONILHA NETO, L. M. Selection for yearling weigth in Nelore and Guzerá zebu breeds: selection applied and response. in 15 years of progeny. In: WORLD CONGRESS ON GENETICS APPLIED TO LIVESTOCK PRODUCTION, 6, Armidale, 1998. Proceedings. Armidale: NSW, 1998. p. 133-136.

RAZOOK, A. G.; FIGUEIREDO, L. A.; TROVO, J. B. F. Intensidades de seleção e respostas diretas e correlacionadas em 10 anos de progênies de bovinos das raças Nelore e Guzerá selecionadas para peso pós-desmame. Boletim de Indústria Animal, v.50, n.2, p.147-163, 1993.

RAZOOK, A. G.; BONILHA NETO, L.M.; FIGUEIREDO, L. A. et al. Seleção para peso pós desmame em bovinos Nelore e Guzerá I. Diferenciais e intensidades de seleção. Boletim de Indústria Animal, v.45, n.2, p.241-271, 1988a. 
RAZOOK, A. G.; BONILHA NETO, L.M.; FIGUEIREDO, L. A. et al. Seleção para peso pós desmame em bovinos Nelore e Guzerá II. Respostas direta e correlacionadas. Boletim de Indústria Animal, v.45, n.2, p.273-315, 1988 b.

RAZOOK, A. G.; FIGUEIREDO, L. A.; CYRILLO, J. N. S. G. et al. Prova de ganho de peso: normas adotadas pela Estação Experimental de Zootecnia de Sertãozinho. Nova Odessa: Instituto de Zootecnia, 1997. 42 p. (IZ. Boletim Técnico, 40).

RAZOOK, A. G.; FIGUEIREDO, L. A.; NARDON, R. F. et al. Efeitos de raça e da seleção para peso pós-desmame sobre características de confinamento e de carcaça da $15^{\text {a }}$ progênie dos rebanhos Zebu e Caracu de Sertãozinho (SP). Revista Brasileira de Zootecnia, v.30, n.1, p.115-124, 2001a.

RAZOOK, A. G.; NARDON, R. F.; TEDESCHI, L. O. et al. Estimativas da composição física das carcaças e do corpo vazio de amostras da $15^{\mathrm{a}}$ progênie dos rebanhos Zebu e Caracu de Sertãozinho (SP). Revista Brasileira de Zootecnia, v.30, n.3, p.10371043, 2001b.

REID, J. T.; BENSADOUN, A.; BULL, L. S. et al Some peculiarities in the body composition of animals. In: NATIONAL ACADEMY OF SCIENCES, Columbia, 1968. Proceedings. Columbia: University of Missouri, 1968. p. 19-44.

REID, J. I.; WHITE, D.; ANRIQUE, R. et al. Nutritional energetics of livestock; some present boundaries of knowledge and future research needs. Journal of Animal Science, v.51, n.6, p.1393-1415, 1980.

RESENDE, F. D.; NARDON, R, F.; RAZOOK, A. G. et al. Desempenho e características de carcaça de zebuínos e Caracu selecionados para peso aos 378 dias de idade, submetidos a dois níveis de energia na terminação. (compact disc). In: REUNIÃO ANUAL DA SOCIEDADE BRASILEIRA DE ZOOTECNIA, 37., Viçosa, 2000. SBZ 2000: trabalhos. Viçosa: SBZ, 2000.

RESENDE, F. D.; OLIVEIRA, J. V.; RAZOOK, A. G. et al. Avaliação das características de carcaça de Zebu e Caracu selecionados para peso aos 378 dias de idade, submetidos a dois níveis de energia na terminação. (compact disc). In: REUNIÃO ANUAL DA SOCIEDADE BRASILEIRA DE ZOOTECNIA, 38., Piracicaba, 2001. SBZ 2001: trabalhos. Piracicaba: SBZ, 2001. 
SAS. INSTITUTE., SAS OnlineDoc: version 8. Cary, SAS Institute, 1999.

SILVA, J. A.II V.; RAZOOK, A. G.; TONHATI, H. et al. Efeito da seleção para peso pós-desmama sobre indicadores da eficiência produtiva de vacas da raça Nelore. Revista Brasileira de Zootecnia, v.29, n.4, p.1020-1027, 2000.

SIMM, G. The use of ultrasound to predict the carcass composition of live cattle- A review. Commonwealth Bureau of Animal Breeding and Genetics, v.51, n.12, p.853-872, 1983.

TEDESCHI, L. O.; BOIN, C.; FOX, D. G. et al. Energy requirement for maintenance and growth of Nellore bulls and steers fed high-forage diets. Journal of Animal Science, v.80, n.6, p.1671-1682, 2002. 